\title{
Niosomes: A novel targeted drug delivery system
}

Iman Akbarzadeh ${ }^{1, *}$, Kamand Sedaghatnia ${ }^{2}$, Mahsa Bourbour ${ }^{3}$, Zahra Salehi Moghaddam ${ }^{4}$, Maryam $^{2}$ Moghtaderi $^{5}$, Ehsan Samimi-Sohrforozani ${ }^{6}$, Sameer Quazi ${ }^{7,}$, Bahareh Farasati Far ${ }^{8,}$.

1. Department of Chemical and Petrochemical Engineering, Sharif University of Technology, Tehran, Iran, iman.akbarzadeh@che.sharif.edu

2. Department of Applied Chemistry, Azad University of Tehran South Branch, Iran, Kamand.niaa@gmail.com

3. Department of Biotechnology, Alzahra University, Tehran, Iran, m.bourbour1@yahoo.com

4. Department of Microbial Biotechnology, School of Biology, College of Science, University of Tehran, Tehran, Iran, zahra98.s.m@gmail.com

5. School of Chemical Engineering, College of Engineering, University of Tehran, Tehran, Iran, mmoghtaderi90@gmail.com

6. Chemical Engineering Department, University of Kashan, Kashan, Iran, Ehsansamimi2022@gmail.com

7. GenLab Biosolutions Private Limited, Bangalore, Karnataka, India, colonel.quazi@gmail.com

8. Department of Chemistry, Iran University of Science and Technology, Tehran, Iran, bahar.ferasati@gmail.com

Corresponding authors: Iman Akbarzadeh; Sameer Quazi; Bahareh Farasati Far 


\begin{abstract}
Nanotechnology is making significant transformation to our world, especially in healthcare and the treatment of diseases. It is widely used in different medical applications, such as in treatment and detection. Targeting diseased cell with nanomedicines is one of the numerous applications of nanotechnology. Targeted drug delivery systems for delivering various types of drugs to specific sites are such a dynamic area in pharmaceutical biotechnology and nanotechnology. Compared to conventional drugs, nanomedicines have a higher absorption and bioavailability rate, improving efficacy and minimizing side effects. There are several drug delivery systems including metallic nanoparticles, polymers, liposomes, and microspheres, but one of the most important is the niosomes, which are produced by nonionic surfactants. Because of the amphiphilic nature and structure, hydrophilic or hydrophobic drugs can be loaded into niosome structures. Other compounds, including cholesterol, can also be applied to the niosomes' backbone to rigidize the structure. Several variables such as the type of surfactant in niosome production, the preparation method, and the hydration temperature can affect the structure of the niosomes. Nevertheless, in-silico design of drug delivery formulations requires molecular dynamic simulation tools, molecular docking, and ADME (absorption; distribution; excretion; metabolism) properties, which evaluate physicochemical features of formulation and ADME attitudes before synthesis, investigating the interaction between nanocarriers and specific targets. Hence, experimenting in-vitro and in-vivo is essential. In this review, the basic aspects of niosomes are described including their structure, characterization, preparation methods, optimization with in-silico tools, factors affecting their formation, and limitations.
\end{abstract}

Keywords: Targeted drug delivery, Niosomes, Structure, Characterization, Preparation, In-silico 


\section{Introduction}

The discovery of nanotechnology in 1959 by Richard Feynmann enabled scientists to investigate the application of nanotechnology in different areas [1]. Nanotechnology has gained specific attention in medicine and medical care. Thanks to nanotechnology, nanoparticles developed to aid and accelerate some health problems. Some diseases, including cancer and fungal diseases, are considered unsolved medical conditions because: 1 . The high toxicity of the therapeutic moiety and the narrow therapeutic window led to serious adverse drug reactions. 2: The time required for treatment is relatively long, resulting in ocular toxicity, hepatotoxicity, and nephrotoxicity [2-4]. The most notable problems with therapeutic molecules are low permeability and solubility, which results in low absorption and bioavailability $[5,6]$. To overcome these limitation, nanoparticles (nanomedicines) provide much more desirable outcomes compared to conventional medicines. Today, vesicular systems, including niosomes, have become valuable tools in biochemical and pharmaceutical applications. The concept of nanomaterials as carriers in drug delivery systems (DDS) is designed to maximize the active agent (drug) concentration in tissues affected by the disease while protecting healthy cell organs. Different nano-carriers, including lipid nanoparticles (liposomes, niosomes), synthetic polymers, metal nanoparticles, nanocrystals, micelles, and dendrimers, are used to transfer medication to target cells [7-10]. Niosomes are self-assembly vesicles made of nonionic surfactants, which are formed by hydration with a unilamellar or multilamellar structure. Niosomes are usually stabilized by the addition of lipids, like cholesterols. The stability, cost-efficiency, and bioavailability of the vesicles have made them one of the best nano-carriers in drug and gene delivery systems [11-13]. On account of their amphiphilic properties, niosomes are excellent for both hydrophobic and hydrophilic drugs. The medication is housed in the lipid bilayer and the inner aqueous compartment, respectively [14, 15]. Peptide drugs, such as insulin and bovine serum albumin (BSA), are remarkably stable in niosomal particles [16]. They are used in anti-AIDS drugs, anticancer drugs, and antibacterial drugs [17-22]. Drug-loaded niosomes are used in anti-cancer drugs, such as breast cancer, brain tumors, and prostate cancer [20, 23-25]. Niosomes, which contain drugs, can be applied in different routes such as intramuscular, intravenous, peroral, and transdermal [26]. Niosomes are capable of transferring API to various parts of the biological system, including across blood-brain barriers [27]. Drug delivery through niosomes has more benefits compared to other ionic carriers, namely liposomes. Niosomes are less toxic, more biodegradable, more stable, and more biocompatible [28, 29]. Due to their bilayer structure, they can release drugs in a controlled way [26, 30-32]. Development in pharmacokinetics of nanomedicines in the body enables them to stay longer in the body and distribute the active pharmaceutical ingredient (API) more effectively to target cells, increasing the efficacy and reducing adverse reactions [33]. Controlling the physiochemical properties of nanodrugs, such as composition and formulation, affects the efficacy and toxicity of nanoparticles. Late clearance of the niosome formulation improves therapeutic performance in a way that the biological environment can no longer harm the active agents [34]. Furthermore, niosomes are desirable carriers of poorly absorbable drugs, such as vinpocetine and simvastatin, by increasing their oral bioavailability and gastrointestinal absorption [35-37]. Meanwhile, niosomes have some drawbacks. To name a few: aggregation, leaking or hydrolysis of the active agent (drug), and fusion of vesicles [33]. Another disadvantage of niosomes is due to aqueous suspension of niosomes, which may lead to hydrolysis of the drug in the structure [38].

On the other hand, the unreliable connection between the formulation and features of nano-carriers is an issue for pharmaceutical companies. Therefore, computational chemistries, such as theoretical methods, molecular docking, ADME (Absorption, distribution, excretion, metabolism) properties, and molecular simulations, have been investigated in drug delivery systems [39-41]. This review provides an extensive viewpoint on niosome structure, niosome preparation methods, niosome characterization, in-silico prediction of niosome, etc., which is still in its infancy. 


\section{Niosomes}

Compared to liposomes, niosomes, as shown in Figure 1, are non-ionic vesicles that are composed of two layers. Niosomes are chemically more stable and less costly than liposomes. The noticeable feature of the niosome structure is that they contain both a hydrophilic head and a hydrophobic tail. It means they are able to entrap a large diversity of drugs (hydrophilic and lipophilic) in their formation. Hydrophilic drugs are loaded into the aqueous core of the niosome, at the same time that the lipophilic domain of the bilayer consists of lipophilic drugs [42]. Mainly, niosomes are made of nonionic surfactants, a hydration medium, and lipids, including cholesterol. The efficacy of a vesicular system is completely dependent on its components. It is also highly essential to understand the basic structural elements of niosomes prior to preparation, as it provides general insight into the mechanism of niosomes and encapsulated drugs. They are considered unilamellar or multilamellar; unilamellar niosomes are bilayer structures, while multilamellar niosomes contain at least 2 bilayer vesicles. The size of the niosome structure is variable from 10 to $1000 \mathrm{~nm}$ and they are categorized as small unilamellar vesicles (SUV), large unilamellar vesicles (LUV), and multi-lamellar vesicles (MLV) [43]. From a thermodynamic point of view, SUVs are less stable than other forms of niosomes, and they are able to encapsulate a lower concentration of hydrophilic drugs while tending to form aggregates. LUVs have a large water portion that is suitable for encapsulating hydrophilic drugs.

MLVs can be produced without the need for complicated methods and are more rigid than the other two forms of niosomes. In addition, they are suitable for the encapsulation of lipophilic drugs due to the existence of multiple bilayer membranes $[38,44]$.

\section{Components of Niosome}

\subsection{Nonionic surfactant}

Nonionic surfactants are a major component of the structure of niosomes and are superior in terms of toxicity, stability, and compatibility with anionic and cationic surfactants. Non-ionic surfactants are less toxic, less hemolytic, and stimulate cell surfaces. They also maintain a physiological $\mathrm{pH}$ in the solution [45]. Nonionic surfactants are considered amphiphilic molecules with two distinct regions (a hydrophilic end and a lipophilic end). These two parts are usually connected by ether, ester bonds, or amide [44]. The hydrophilic-lipophilic balance (HLB) of the surfactant determines the formation of the bilayer structure of the vesicles. HLB value is an important feature in controlling the entrapment of vesicles. This dimensionless factor is also known to be a time-efficient guide for the selection of surfactants. The HBL value for non-ionic surfactants is 0 to 20. An HBL value of 14 to 17 is not acceptable to produce niosomes, whereas the highest entrapment efficiency occurs at an HBL value of 8.6. The encapsulation efficiency lowers as the HBL goes down from 8.6 to 1.7 [38, 46, 47].

Non-ionic vesicles can be composed of various sorts of molecules, namely alkyl esters, fatty acids, amides, amino acids, and alkyl ether surfactants. Alkyl ether surfactant is widely utilized to prepare nonionic surfactants as they make relatively stable niosomes, which are used to encapsulate proteins and peptides [48]. Non-ionic surfactants, in niosome preparation, are amphipathic, containing alkyl oxyethylene, terpenoids, polysorbates, and spans [49-53].

The chain length of the alkyl oxyethylene group is usually $\mathrm{C} 12$ to $\mathrm{C} 18$. The trapping efficiency of non-ionic surfactants made with stearyl (C18) is greater than that of lauryl (C12). The formulation of niosomes with squalene (terpenoid) enhances stability and hardness, indicating negligible cytotoxicity in vivo and in vitro [51]. Polysorbates are also common in niosome preparation. Due to the polyethylene glycol present in polysorbates 80 , niosomes prepared with this non-ionic surfactant are perfect for the gene delivery system [52]. Due to the connection of the entrapped drug and acyl chains 
of Span 60, niosomes with Span 60, Tween 60, and cholesterol show a notably high entrapment efficiency compared to other Span groups. [53] In a study in 2001, niosomes containing salbutamol sulfate were prepared by different surfactant types such as Tween 20,40,60, 80, and Brij 35 using the transmembrane $\mathrm{pH}$ gradient method. Span 60 was the most acceptable surfactant, accounting for $78.4 \%$ of drug release in $24 \mathrm{~h}$ and $87.51 \pm 0.239 \%$ entrapment efficiency [54].

\subsection{Cholesterol}

Since steroids, such as cholesterol (CHOL) boost the physical structure and property of non-ionic vesicles, they are important components in the formation of niosomes. It is shown that cholesterols have a positive effect on rigidity, permeability, leakage, and entrapment efficiency. Cholesterol is an amphiphilic molecule. The $\mathrm{OH}$ group is placed in the aqueous part, while the hydrocarbon surfactant chain faces the aliphatic chain. As the firm skeleton of cholesterol places itself in the bilayer of the niosome, they become more rigid by limiting the movement of carbon of hydrocarbons, which is practical under intense stress conditions [42]. Preparation of niosomes with cholesterols also makes them less permeable against the destructive impact of plasma and serum components; decreasing the leakage proportion. The permeability of niosomes prepared with 5, 6-carboxy fluorescein (CF) is reduced 10 times after adding cholesterol to the formulation $[34,55]$. A nonionic hydrophilic surfactant such as decyl polyglycolide can only form a stable, spherical vesicle in the presence of a high volume of CHOL. As a result, $\mathrm{CHOL}$ also improves the cohesion of the niosomal membrane [56]. As the HBL value goes above 10, we should add to the minimum cholesterol concentration to compensate for the large head groups of the surfactant. Niosomes with a high proportion of CHOL show a higher entrapment efficiency, while no considerable growth was indicated in the Brij 52 (HLB 5.3) niosomes. In fact, after exceeding a precise proportion of cholesterol, the efficiency of trapping saw a reduction [11].

\section{Hydration medium}

Hydration medium is a considerable factor in the formation of niosomes, as it has a straight impact on particle size. In the formulation of niosomes, phosphate buffer with various $\mathrm{pH}$ values is widely utilized as a hydration medium. The solubility of the encapsulated active agent dictates the $\mathrm{pH}$ of the hydration medium. In the preparation of ketoconazole niosomes, a $5.5 \mathrm{pH}$ phosphate buffer was used whereas for preparing meloxicam niosomes the $\mathrm{pH}$ of the phosphate buffer was 7.4. [57, 58]. Mokhtar et al. [59] prepared flurbiprofen-loaded proniosomes with Sorensen's phosphate buffer ( $\mathrm{pH}$ 7.4) as hydration medium, resulting in $72.25 \pm 2.3 \%$ entrapment efficiency. Regarding the size of the niosomes, the smallest particles were produced using Tris, distilled water (DW), and HEPES (4-(2hydroxyethyl)-1-piperazineethanesulfonic acid) as hydration medium. (60.96 $\pm 0.36 \mathrm{~nm}, 71.83 \pm 0.44$ $\mathrm{nm}, 74.10 \pm 0.51 \mathrm{~nm}$, respectively) [60].

\section{Methods of prep}

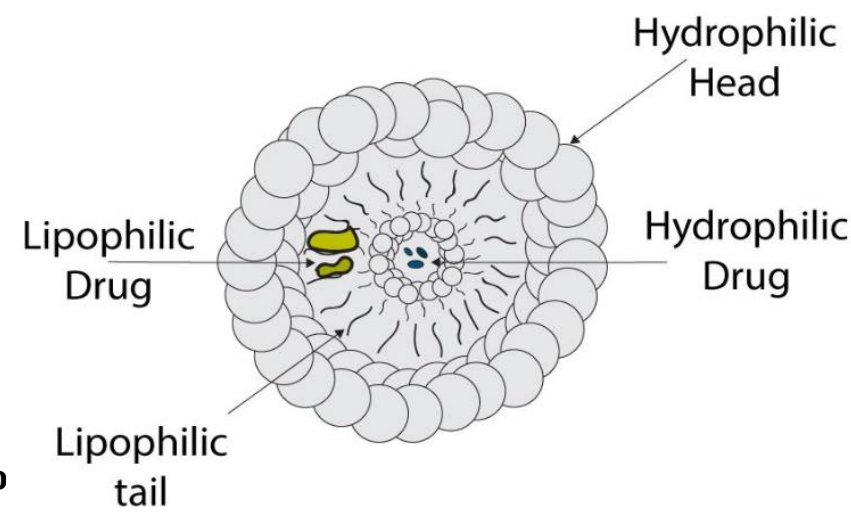

Figure 1. illustrative sdepiction of niosome

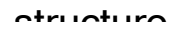


As the method of niosome preparation directly affects vesicle size and distribution, entrapment efficiency, the number of double layers, and permeability of vesicle membrane, it is important to fully comprehend the techniques before selecting the best method for niosome preparation. Multiple methods for the preparation of niosomes have been introduced, yet only a limited number of these methods such as ether injection, hand shaking (TFH), sonication, Micro fluidization are considered standard [61]. Generally, niosome preparation is easier than liposome preparation, as nonionic surfactants are steadier against air oxidation than phospholipids. For targeting the cells, niosomes can be also coated with a different agent, including polyethylene glycol (PEG), hyaluronic acid (HA), and antibodies [44, 62-65]. In general, all of the niosome preparation techniques are included in two categories [66]:

\section{1- Passive trapping techniques}

This technique involves most methods of preparing niosomes, in which the drug is encapsulated during the process of niosome production.

\section{2- Active trapping techniques}

In active trapping techniques, after the niosome preparation is complete, the drug is loaded while the ion gradient or $\mathrm{pH}$ gradient is kept to enable the absorption of the drugs in the niosomes. Benefits of this method include; cost-effectiveness, leakage reduction, and suitability for thermosensitive drugs. The preparation of niosomes begins by hydrating the surfactant and lipid mixture at high temperatures and then optionally increasing the size to acquire a colloidal suspension. The nested drug is then removed by centrifugation, gel filtration, or dialysis [61]. More information on particle size, benefits, and drawbacks of the preparation techniques is presented in Table $\mathbf{1 .}$

Table 1. Different preparation methods and their properties.

\begin{tabular}{|c|c|c|c|c|c|}
\hline $\begin{array}{l}\text { Preparation } \\
\text { Method }\end{array}$ & $\begin{array}{l}\text { Type of } \\
\text { niosome }\end{array}$ & Advantage & Disadvantages & $\begin{array}{c}\text { Preparation } \\
\text { category }\end{array}$ & References \\
\hline $\begin{array}{c}\text { TFH } \\
\begin{array}{c}\text { (Hand shaking) } \\
\text { method }\end{array}\end{array}$ & MLV & $\begin{array}{l}\text { A simple technique for } \\
\text { laboratory research }\end{array}$ & $\begin{array}{l}\text { includes the use of } \\
\text { organic solvent }\end{array}$ & $\begin{array}{l}\text { Passive } \\
\text { trapping }\end{array}$ & {$[38,67]$} \\
\hline $\begin{array}{l}\text { Multiple membrane } \\
\text { extrusion method }\end{array}$ & SUV & $\begin{array}{l}\text { An acceptable method for } \\
\text { niosome size control }\end{array}$ & $\begin{array}{l}\text { Involves the use of } \\
\text { organic solvent }\end{array}$ & $\begin{array}{l}\text { Passive } \\
\text { trapping }\end{array}$ & {$[67]$} \\
\hline RPE method & MLV/LUV & High Entrapment efficiency & $\begin{array}{l}\text { includes the use of } \\
\text { organic solvent }\end{array}$ & $\begin{array}{l}\text { Passive } \\
\text { trapping }\end{array}$ & {$[68]$} \\
\hline $\begin{array}{l}\text { Ether injection } \\
\text { method }\end{array}$ & SUV/LUV & $\begin{array}{l}\text { A simple method for } \\
\text { laboratory research }\end{array}$ & $\begin{array}{l}\text { Not suitable for heat- } \\
\text { labile drugs }\end{array}$ & $\begin{array}{l}\text { Passive } \\
\text { trapping }\end{array}$ & [69] \\
\hline $\begin{array}{l}\text { Micro fluidization } \\
\text { method }\end{array}$ & MLV & no organic solvent required & $\begin{array}{l}\text { Not suitable for heat- } \\
\text { labile drugs }\end{array}$ & $\begin{array}{l}\text { Passive } \\
\text { trapping }\end{array}$ & {$[42,44]$} \\
\hline $\begin{array}{c}\text { Trans membrane } \\
\text { pH gradient } \\
\text { method }\end{array}$ & MLV/SUV & High entrapment efficiency & $\begin{array}{l}\text { Involves the use of } \\
\text { organic solvent }\end{array}$ & $\begin{array}{l}\text { Active } \\
\text { trapping }\end{array}$ & {$[70]$} \\
\hline Sonication method & SUV/LUV & $\begin{array}{c}\text { no organic solvent } \\
\text { involved/ }\end{array}$ & & $\begin{array}{l}\text { Passive } \\
\text { trapping }\end{array}$ & {$[71]$} \\
\hline
\end{tabular}


eco-friendly/ produces

small niosome particles

\section{Lipid injection} method

\section{SUV/LUV}

no organic solvent involved cannot be used for

heat-labile drugs
Passive

trapping

$[44,72]$

TFH (Thin Film Hydration)

RPE (Reverse Phase Evaporation) method

LUV size $=>0.10 \mu \mathrm{m}$

\subsection{Ether injection method}

The drug and lipid (Figure 2) are added to diethyl ether and gradually to the aqueous phase through a 14 -gauge needle at $0.25 \mathrm{ml} / \mathrm{min}$, which is maintained at $60^{\circ} \mathrm{C}$. When the organic solvent is heated above the boiling point, large unilamellar niosomes are produced, which can be further treated to obtain reduced niosomes in size. Using the ether injection method, Baillie et al. [73] were successful in the preparation of salbutamol niosomes with an entrapment efficiency of $67.7 \%$.

\subsection{Thin film hydration method (hand shaking)}

The thin-film hydration method (Figure 3) is the most widely used, repeatable, and studied technique to produce multilayer vesicles (MLV). After dissolving surfactant and cholesterol in a volatile solvent such as diethyl ether, chloroform, or methanol in a round bottom flask, dissolve the niosomes by thinlayer hydration, then remove the organic solvent by a rotary evaporator at room temperature $\left(20^{\circ} \mathrm{C}\right)$. This creates a thin layer of solid mixture on the wall of the flask. While stirring gently, the dried surfactant can be hydrated with the aqueous phase including the drug at $0-60^{\circ} \mathrm{C}$. Fig. 3. This process forms typical multilamellar niosomes [12, 30]. Imran Khan et al. [42] synthesized diaceteine containing niosomes to treat joint disease by thin layer hydration.

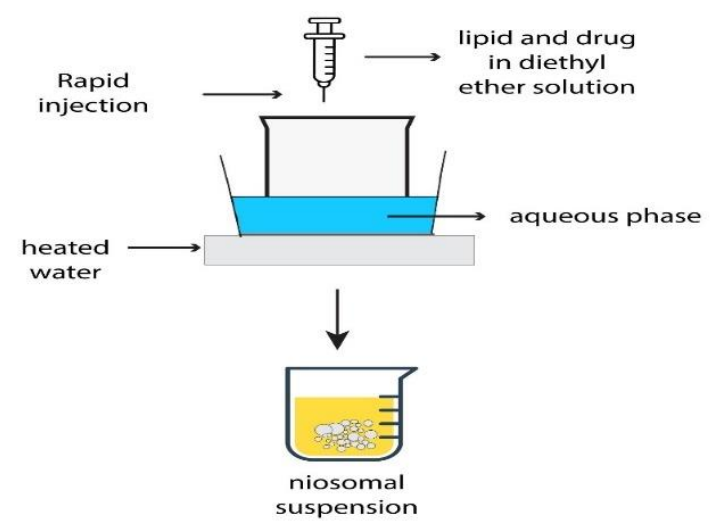

Figure 2. Illustrative depiction of the preparation of niosomes with the ether injection method. 


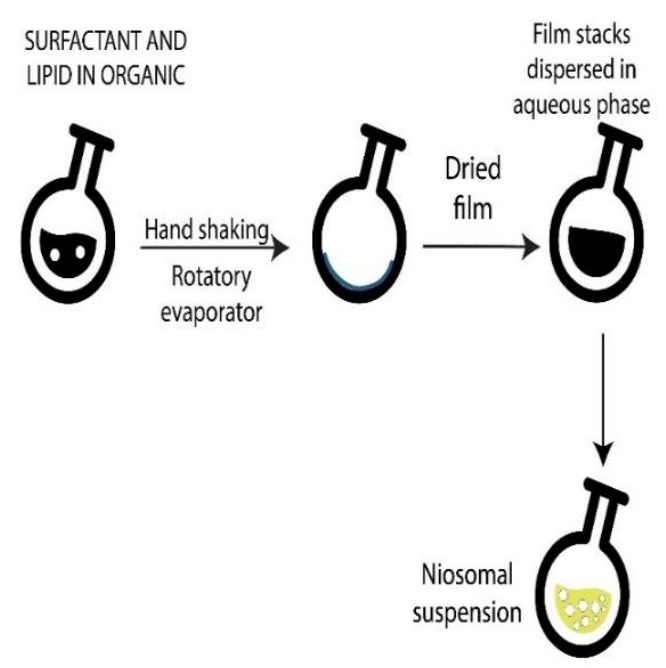

Figure 3. Illustrative depiction of the preparation of niosomes with the thin film hydration (hand shaking) method.

\subsection{Multiple membrane extrusion method}

This is an acceptable way to control the size of niosomes. With a mixture of surfactant, cholesterol, and diacetyl phosphate in chloroform, a thin layer is produced by evaporation. This product is hydrated with an aqueous medicinal solution (Figure 4) [42]. The suspension is extruded through polycarbonate membranes and then placed in up to 8 passages [30].

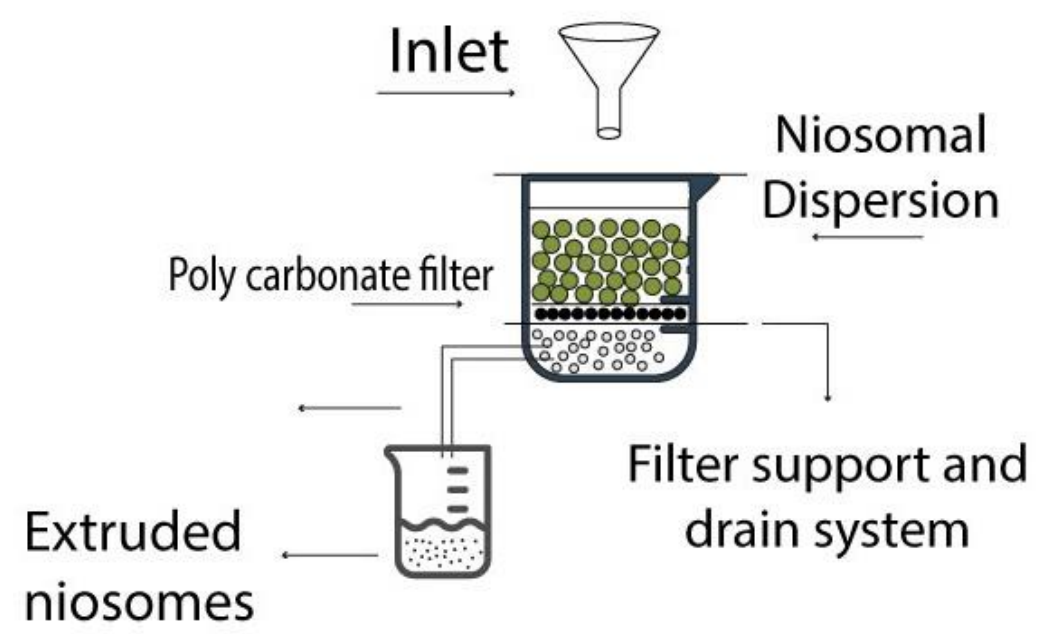

Figure 4. Illustrative depiction of the preparation of niosomes with the multiple membrane extrusion method.

\subsection{Reverse phase evaporation method}

Surfactant and cholesterol are dissolved in chloroform and ether. An aqueous phase including the drug is added to the mixture and then ultrasound is performed at $4-5^{\circ} \mathrm{C}$. A small proportion of buffer salt 
is then included in the compound, producing a more sonic gel. The organic solvent is withdrawn at 40 ${ }^{\circ} \mathrm{C}$ under low pressure. After diluting the resultant suspension with PBS, we heated the mixture in a water bath at $60^{\circ} \mathrm{C}$ for 10 minutes to form large monolayers (Figure 5). Guinedi et al [74] produced acetazolamide niosomes with REV for the treatment of glaucoma with a $65.71 \% \pm 1.09$ encapsulation efficiency [30].

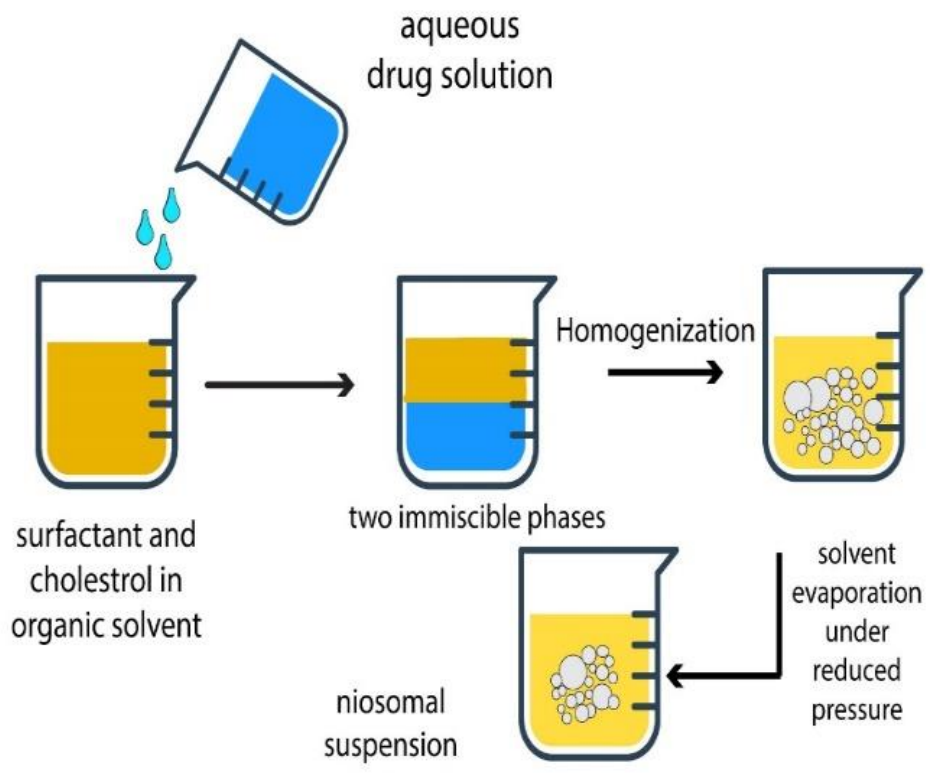

Figure 5. Illustrative depiction of the preparation of niosomes with the reverse phase evaporation method.

\subsection{Sonication method}

A standard method of producing vesicles is the ultrasound technique. An aqueous phase containing the active agent in the buffer is included in a mixture (cholesterol/surfactant) in a $10 \mathrm{ml}$ glass vial. For 3 minutes, sonication in a sonic titanium probe is applied to the mixture at $60^{\circ} \mathrm{C}$, yielding small and uniform niosomes in size. Niosomes loaded with rifampicin were produced using the probe sonication method as a drug model for low-soluble drugs [30, 71, 75] (Figure 6). 

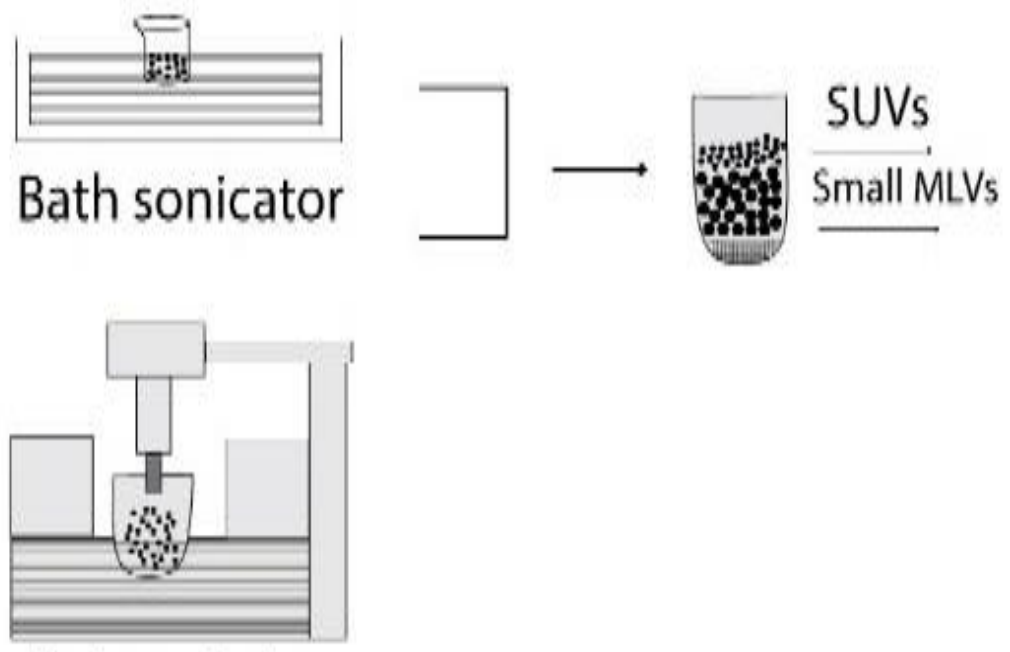

Probe sonicator

Figure 6. Illustrative depiction of the preparation of niosomes with the sonication method

\subsection{Micro fluidization}

Micro-fluidization (Figure 7) is a current approach to prepare niosomes by specified size distribution. This method is formed on the jet principle. That is to say, mix two different fluids, namely water and alcohol, in the microchannel. The surfactant solution and the drug are pumped under tank pressure through ice-filled interactions. The mixture is then passed through a cooling ring to withdraw the heat generated in the course of micro-fluidization. The recirculation or removal happens when the solution reinterns the reservoir. This is repeated to obtain the proper size of the size of the vesicle [11]. Obeid et al. [76] prepared siRNA-containing niosomes in the treatment of cancer cells. The niosomes were monodisperse and small (less than $60 \mathrm{~nm}$ ), considered an efficient size range for drug delivery systems.

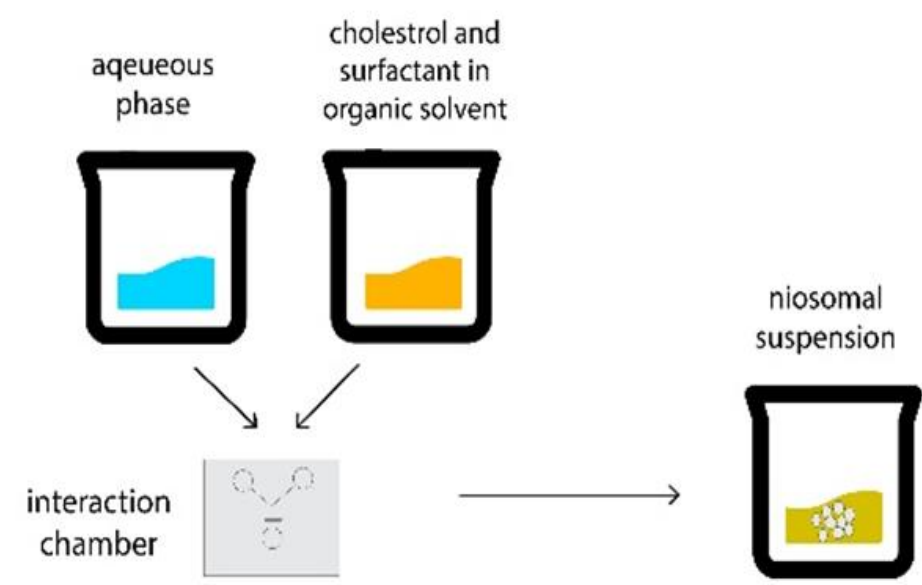

Figure 7. Illustrative depiction of the preparation of niosomes with Microfluidization method. 


\subsection{Lipid injection method}

In this method, there are no organic solvents involved, which are both expensive and highly toxic for in vivo use. The molten surfactant and cholesterol are added to a heated aqueous phase, including dissolved drug molecules, resulting in niosome formation(Figure 8) [77].

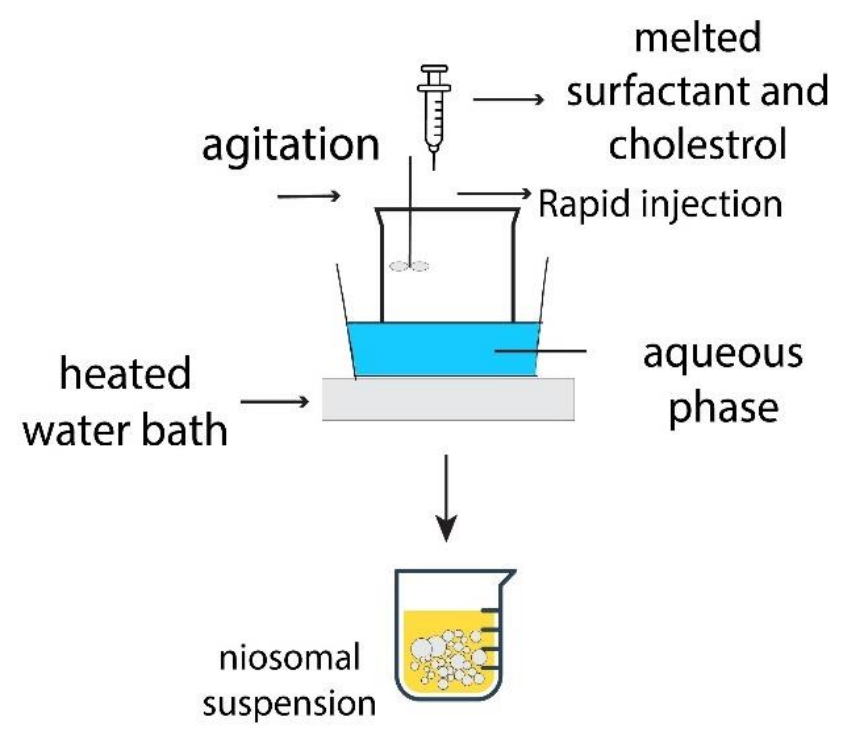

Figure 8. Illustrative depiction of the preparation of niosomes with the lipid injection method.

\subsection{Transmembrane pH gradient method}

In this method, the same amount of cholesterol and surfactant is added to chloroform. Under low pressure, the evaporated solvent forms a thin film on the wall of the round bottom flask. The resulting film is hydrated with $300 \mathrm{ml}$ of citric acid (pH 4.0) using a vortex mixer. The following vesicular particles undergo freezing and thawing cycles. After adding an aqueous solution to the mixture, the $\mathrm{pH}$ of the sample increases to 2.7-7.2 by adding a solution of sodium hydrogen phosphate. (Figure 9) The suspension is then heated to $60^{\circ} \mathrm{C}$ to form multilayered niosomes for 10 minutes [30]. 


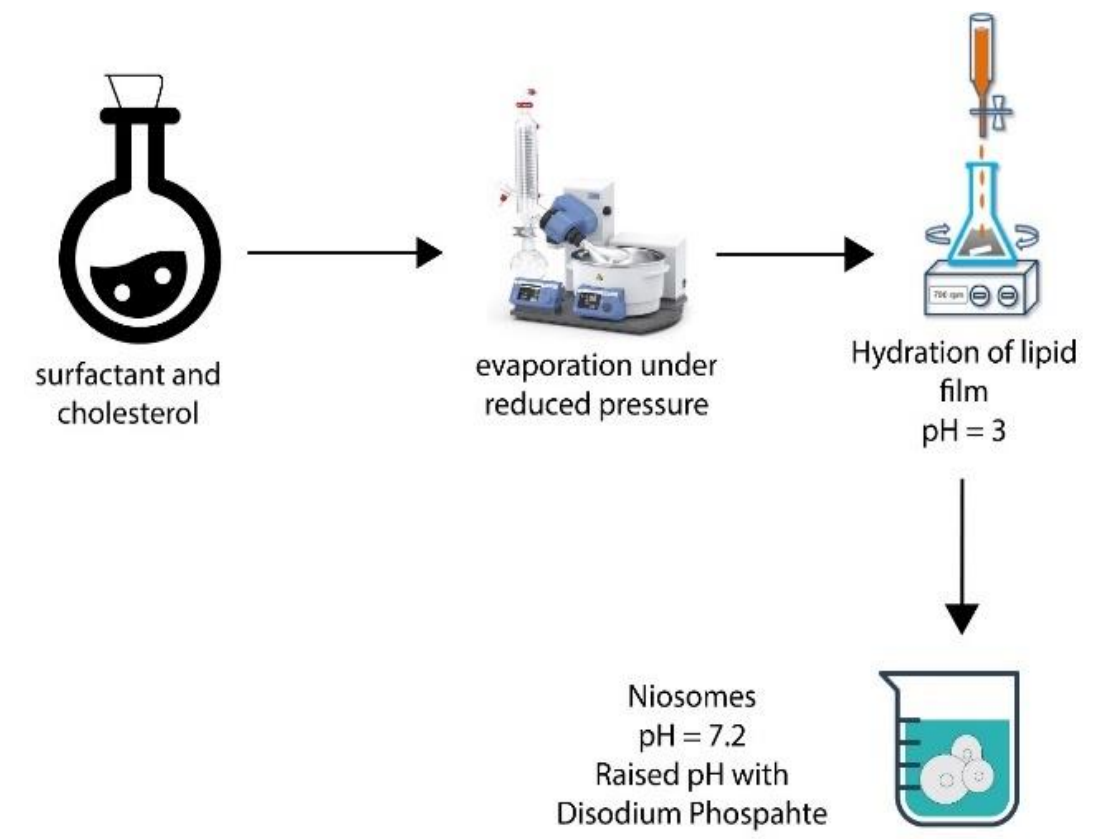

Figure 9. Schematic diagram of the preparation of niosomes via trans membrane pH gradient.

\section{Comparative assessment of niosomes produced by different methods}

Baillie et al. [34] compared niosomes, which were produced by injection of ether, hand shaking and sonication methods. The entrapment efficiency of the ether-injected niosomes was noticeably higher than that for hand-shaken and sonicated vesicles. While niosomes prepared with sonication had the lowest mean size value $(152.5 \pm 81.6 \mathrm{~nm})$, ether-injected and hand-shaken niosome particles were higher in size ( $306.0 \pm 178.0 \mathrm{~nm}$ and $490.0 \pm 378.0 \mathrm{~nm}$, respectively). Guinedi and Mortada et al. [74] compared acetazolamide-loaded niosomes, produced by the RPE and TFH method. After 8 hours of niosome storage, the MLVs, produced by the TFH method, showed higher entrapment efficiency than those produced with RPE. Multilamellar niosomes obtained particle sizes higher than those of REV. Generally, multilamellar acetazolamide niosomes were considered to be more efficient and presented a prolonged decrease in IOP. Key Yeo et al. [78] produced niosomes loaded with Cinnarizine, processed by the TFH and the micro fluidization method. MLVs produced by thin-film hydration have greater particle size distribution from 827 to $7320 \mathrm{~nm}$ and a greater polydispersity index (PDI) of 0.3 to 0.9 , while niosomes prepared by the microfluidic method produced smaller vesicles (ranging from 155 to $355 \mathrm{~nm}$ ) and lower PDI value (0.011 to 0.209). The entrapment efficiency of niosomes produced by microfuidization and TFH method was noticeably low ( $\geq 9 \%$ and $\geq 20$, respectively). Bhaskaran et al. [79] prepared salbutamol sulfate-containing niosomes using Span 60 as a surfactant using various methods such as TFH, ether injection, lipid layer hydration, and membrane $\mathrm{pH}$ gradient method. Encapsulation efficiency varies between $62 \%$ to $82 \%$. The membrane $\mathrm{pH}$ gradient method was the most satisfying technique that showed a $78.4 \%$ drug release in a day and an $87.51 \pm 0.239 \%$ entrapment efficiency. Gim Ming Ong et al [67] studied the efficiency of various methods for nanosizing liposomes.

These liposomes were assayed by extrusion, ultrasound, freeze-thaw sonication (FTS), ultrasound, and nano synthesis. Among the methods, the extrusion method was more efficient, reducing its size to 67.9. FTS, ultrasound, and sonication followed, with reductions of $61.2 \%, 26.7 \%$, and $15.0 \%$, respectively. The homogenization method was found to be less efficient. A detailed example of drugloaded niosomes and their properties is provided in Table 2. 
Table 2. Drug-loaded niosomes and their characteristics.

\begin{tabular}{|c|c|c|c|c|c|}
\hline $\begin{array}{l}\text { Methods of } \\
\text { preparation }\end{array}$ & Drug & Composition & solvent & Application & References \\
\hline $\begin{array}{l}\text { Ether injection } \\
\text { method }\end{array}$ & Methotrexate & $\begin{array}{l}3 \text { p-d Glucopyranosides } \\
\text { (octyl, decyl, dodecyl), } \\
\text { cholesterol, } \\
\text { dicetylphosphate }\end{array}$ & $\begin{array}{l}\text { Chloroform/ } \\
\text { Methanol }\end{array}$ & anticancer & {$[80]$} \\
\hline TFH & Paclitaxel & Span 40, cholesterol, DCP & Chloroform & anticancer & {$[81]$} \\
\hline $\begin{array}{l}\text { TFH, } \\
\text { Sonication (20min) }\end{array}$ & Curcumin & Tween 20, cholesterol & $\begin{array}{l}\text { Chloroform/ } \\
\text { Methanol }\end{array}$ & $\begin{array}{l}\text { anticancer, } \\
\text { antioxidant, anti- } \\
\text { inflammatory }\end{array}$ & {$[81]$} \\
\hline $\begin{array}{l}\text { Probe sonication } \\
\text { method ( } 5 \text { min) }\end{array}$ & Rifampicin & $\begin{array}{l}\text { Span60, Cholesterol, } \\
\text { Pluronic L121, DCP }\end{array}$ & - & $\begin{array}{l}\text { antitubercular, } \\
\text { antimicrobial }\end{array}$ & {$[71]$} \\
\hline REV, TFH & Acetazolamide & Span40, Span60, cholesterol & $\begin{array}{l}\text { Chloroform/ } \\
\text { Methanol }\end{array}$ & glaucoma & {$[74]$} \\
\hline $\begin{array}{l}\text { Ether injection } \\
\text { method }\end{array}$ & $\begin{array}{l}\text { Sodium } \\
\text { stibogluconate }\end{array}$ & Surfactant, cholesterol & Diethyl ether & $\begin{array}{l}\text { visceral } \\
\text { leishmaniasis }\end{array}$ & {$[17]$} \\
\hline TFH & Vinblastine & $\begin{array}{l}\text { Span60, Tween } 60, \\
\text { cholesterol-PEG 600, DCP }\end{array}$ & $\begin{array}{l}\text { Chloroform/ } \\
\text { Methanol }\end{array}$ & anticancer & {$[82]$} \\
\hline $\begin{array}{l}\text { Micro fluidization } \\
\text { method }\end{array}$ & siRNA & $\begin{array}{l}\text { Tween 85, Cholesterol, } \\
\text { DDAB, }\end{array}$ & Ethanol & anticancer & {$[76]$} \\
\hline RPE & Tetanus toxoid & Span 60, cholesterol & Diethyl ether & tetanus & {$[83]$} \\
\hline $\begin{array}{l}\text { Proniosome-derived } \\
\text { niosome method }\end{array}$ & Tenofovir & Span $20,40,60$, cholesterol & Ethanol & Anti-AIDS & {$[84]$} \\
\hline TFH & Embelin & $\begin{array}{l}\text { Span 60, cholesterol, } \\
\text { phospholipid }\end{array}$ & Chloroform & anti-diabetic & {$[85]$} \\
\hline RPE & Ganciclovir & Span 40, 60, cholesterol & $\begin{array}{l}\text { Ether/ } \\
\text { Chloroform }\end{array}$ & $\begin{array}{l}\text { herpes viruses: } \\
\text { varicella-zoster } \\
\text { virus, } \\
\text { cytomegalovirus, } \\
\text { and Epstein-Barr } \\
\text { virus }\end{array}$ & {$[86]$} \\
\hline TFH & Minoxidil & $\begin{array}{l}\text { Brij 52, } 76 \text { and Span 20, 40, } \\
60 \text {, and } 80\end{array}$ & Chloroform & $\begin{array}{l}\text { androgenetic } \\
\text { alopecia }\end{array}$ & {$[87]$} \\
\hline TFH & Nystatin & Span 40 and 60 , cholesterol & Methanol & fungal infection & {$[88]$} \\
\hline
\end{tabular}




\begin{tabular}{|c|c|c|c|c|c|}
\hline RPE & Letrozole & $\begin{array}{l}\text { Span } 60, \text { Tween } 80, \\
\text { cholesterol }\end{array}$ & Alcohol & anticancer & {$[88]$} \\
\hline Sonication method & Diallyl disulfide & $\begin{array}{l}\text { Span } 20,40,60,80 \\
\text { cholesterol, DCP }\end{array}$ & $\begin{array}{l}\text { Phosphate } \\
\text { buffered } \\
\text { saline (PBS) }\end{array}$ & $\begin{array}{l}\text { antibacterial and } \\
\text { antifungal }\end{array}$ & [89] \\
\hline TFH & Morinhydrate (MH) & $\begin{array}{l}\text { Span } 60,80 \text {, Tween } 80, \\
\text { cholesterol }\end{array}$ & $\begin{array}{l}\text { Methanol/ } \\
\text { Chloroform }\end{array}$ & $\begin{array}{l}\text { antimicrobial and } \\
\text { anticancer }\end{array}$ & [90] \\
\hline RPE & Ellagic acid (EA) & $\begin{array}{l}\text { Span-60 and Tween-60, } \\
\text { cholesterol }\end{array}$ & Diethyl ether & antioxidant & [91] \\
\hline $\begin{array}{l}\text { micro fluidization } \\
\text { method }\end{array}$ & Topotecan & $\begin{array}{l}\text { Span } 60 \text {, cholesterol, and } \\
\text { DSPE-PEG(2000) } \\
\text { maleimide }\end{array}$ & Chloroform & Antitumor & {$[92]$} \\
\hline TFH & Hydroxychloroquine & $\begin{array}{l}\text { Brij } 35,52,58,72,76,92, \\
97 \text {, cholesterol, DCP }\end{array}$ & Chloroform & $\begin{array}{l}\text { rheumatoid } \\
\text { arthritis, lupus }\end{array}$ & [48] \\
\hline $\begin{array}{l}\text { Thin-film hydration } \\
\text { method }\end{array}$ & Glucocorticoid & $\begin{array}{l}\text { polysorbate } 20, \text { cholesterol } \\
\text { and BDP }\end{array}$ & $\begin{array}{l}\text { Chloroform/ } \\
\text { Methanol }\end{array}$ & $\begin{array}{l}\text { inflammatory lung } \\
\text { diseases }\end{array}$ & {$[62]$} \\
\hline $\begin{array}{l}\text { Solvent injection } \\
\text { method }\end{array}$ & Gatifloxacin & Span 60 , cholesterol & Chloroform & $\begin{array}{l}\text { Anti-bacterial for } \\
\text { ocular diseases }\end{array}$ & [93] \\
\hline TFH & Doxorubicin & $\begin{array}{l}\text { Span } 40, \text { Tween } 40, \\
\text { cholesterol, Hydrophobin-1 }\end{array}$ & Chloroform & anticancer & {$[7]$} \\
\hline
\end{tabular}

\section{Characterization of niosomes}

Niosome characterization is highly important to understand the behavior and the quality of the vesicles and how they might act in future clinical studies. Characteristics of niosomes including size, size distribution, zeta potential, morphology, entrapment efficiency (EE), and in vitro release study have a significant effect on vesicle rigidity and in vivo performance of the niosomes. Some of the most fundamental parameters are niosome size, EE, and in-vitro drug release. Reasonable vesicle size and EE, cholesterol, and the properties of membrane components, including the loaded drug, all determine to the rigidity of the niosome structure and the encapsulated drug. The method of loading the drug into the vesicle structure also defines the EE rate. As might be anticipated, larger vesicles present higher entrapment efficiency since they have more space to accommodate the active agent. They are summarized in Table 3 and discussed further below [72]. 
Table 3. Evaluation parameters and their related methods.

\begin{tabular}{|l|l|}
\hline $\begin{array}{l}\text { Evaluation parameter } \\
\text { Size and size } \\
\text { distribution }\end{array}$ & $\begin{array}{l}\text { Methods } \\
\text { (TEM) laser light scattering, gel exclusion }\end{array}$ \\
\hline Polydispersity index & Size analyzer \\
\hline Morphology & SEM, TEM, freeze fracture technique \\
\hline Entrapment Efficiency & Centrifugation, Dialysis, Gel chromatography \\
\hline In vitro release & Dialysis membrane, Franz diffusion cells \\
\hline Bilayer Formation & X-cross \\
\hline Zeta potential & Laser Doppler velocimetry \\
\hline
\end{tabular}

\subsection{Size and size distribution}

Niosome size is an important feature in the structure of niosomes because it gives data about particle stability and physical properties. The size of the niosome particles varies from about 10 nanometers to about 50 micrometers. Measurement of niosome size is possible through various methods, namely light scattering techniques (DLS) and light microscopy [38]. DLS should be converted as photon correlation spectroscopy (PCS) [44]. This fast and non-destructive method requires only a low concentration of particle samples. DLS provides not only cumulative information about average particle size, but also particle size distribution [77]. Other techniques, such as electron microscopic analysis (SEM), (TEM), and freeze-fracture replication-electron microscopy (FF-TEM)) are also used. Electron microscopic techniques are acceptable approaches for not only niosomes size but also the number of bilayers [94]. Generally, it should be mentioned that microscopy techniques give artifacts. Consequently, it is suggested to apply several methods to obtain reliable results.

\subsection{Morphology}

Microscopic methods are also applied to study the particle morphology of the niosome structure. Electron microscopy, transmission electron microscopy (TEM) and ice fracture transmission electron microscopy (FF-TEM) techniques are preferably utilized for liquid samples, while scanning electron microscopy (SEM) techniques are used for solid samples [77].

\subsection{Zeta potential}

The surface charge of nanoparticles (zeta potential) provides information about the solidity of the structure of niosomes; thus, it is one of the main factors in characterizing niosome particles. In general, the stability of charged niosomes against aggregation and fusion is higher compared to those of uncharged niosomes [94]. The zeta potential can be done using the laser Doppler velocimetry technique, which indicates the electrostatic interaction between two nanoparticles side by side. Studies show that the zeta potential above $30 \mathrm{mV}$ or less than $30 \mathrm{mV}$ has satisfactory stability [95]. 


\subsection{Bilayer formation}

Niosomes have either unilamellar or multilamellar structures. The assembly of surfactants to form bilayers can be characterized with the aid of X-cross formation under light polarization microscopy [96].

\subsection{Temperature of hydration}

The temperature of hydration is an effective factor in the size and shape of niosome vesicles. It is ideal when the hydration temperature is over the gel to the liquid phase transition of the system. Decreasing or increasing the temperature impacts the grouping of surfactants and the morphology of the niosomes [97].

\subsection{Niosome stability}

The stability of vesicular niosomal bilayer systems is related to physical, biological, and chemical stability. Niosome stability determines the function of niosomes in vitro and in vivo [98]. By studying the size and zeta potential and making changes in these two factors, we can show possible instability. The stability of niosomes is often evaluated within 90 days, in different temperatures $\left(4{ }^{\circ} \mathrm{C}, 25^{\circ} \mathrm{C}, 40\right.$ ${ }^{\circ} \mathrm{C}$,) and a relatively humid atmosphere [99] [100].

\subsection{Entrapment efficiency (EE)}

For the therapeutic use of niosomes, the most fundamental factor is entrapment efficiency [87]. For EE measurement, unloaded drugs (free drug) should be removed from the entire process by centrifugation, gel chromatography, dialysis, or filtration. The drug trapped in the niosomes, with complete withdrawal of the free drug, is determined using 50\% n-propanol or $0.1 \%$ Triton X-100 at approximately 1 hour of incubation [101]. Entrapment efficiency is known as the concentration of loaded drug in the vesicular structure and can be assessed using the following equation.

$\mathrm{EE}=($ Amount of drug entrapped $\div$ Total amount of drug added $) 100 \%$

The entrapped drug concentration is a certain amount of drug that is trapped in the vesicles. The total amount of drug is the total ratio of the primary drug [77].

\subsection{In vitro drug release}

One of the main factors of niosome characterization is in vitro drug release, which is determined by several factors, including the temperature of hydration, the concentration of the drug, and the nature of the membranes. The dialysis membrane is generally used to study the rate of release of active agents (drug molecule) release. In this procedure, a clean dialysis bag is washed and bathed in distilled water. The mixture is then inserted into a piped bag and sealed. The vesicle bag is placed in a $200 \mathrm{ml}$ glass of $(\mathrm{PBS})$ at a continuous temperature $\left(37^{\circ} \mathrm{C}\right)$ under a magnetic stirrer. At predetermined intervals, the samples are exposed to the same proportion of freshly prepared medium. We then analyze the samples using the appropriate methods to assess the volume of the drug released over time $[95,102,103]$. Another method of studying in vitro drug release is the Franz diffusion cell. In this method, proniosomes are placed into a Franz diffusion cell shaped with a cellophane membrane. A suitable release buffer is selected, then the proniosomes are dialyzed at room temperature. The resultant specimens are taken out of the solution at appropriate intervals, and then effective analysis 
for drug content is applied. The methods include U.V. spectroscopy and HPL. [66]. Different drugloaded niosomes are shown in Table 4.

Table 4. Different drug-loaded niosomes and their characterization.

\begin{tabular}{|c|c|c|c|c|c|}
\hline Drug & Method of preparation & $\begin{array}{l}\text { The highest } \\
\text { EE }\end{array}$ & Size & Zeta potential & $\begin{array}{l}\text { Polydispers } \\
\text { ity index }\end{array}$ \\
\hline Methotrexate & Ether injection method & $94.8 \pm 4.6$ & $115.2 \pm 7.0 \mathrm{~nm}$ & ND & ND \\
\hline Paclitaxel & Thin-film hydration method & $98.7 \pm 0.8 \%$ & $134 \pm 3 \mathrm{~nm}$ & $-81.1 \pm 2.2$ & $0.294 \pm 0.006$ \\
\hline Curcumin & $\begin{array}{l}\text { thin film hydration, sonication } \\
(20 \mathrm{~min})\end{array}$ & ND & 80 to $200 \mathrm{~nm}$ & ND & ND \\
\hline Rifampicin & Probe sonication (5 min) & $75.37 \%$ & $\begin{array}{l}190 \mathrm{~nm} \text { to } 893 \\
\mathrm{~nm}\end{array}$ & $-27.5 \pm 0.9$ & $\begin{array}{l}0.381 \pm \\
0.053\end{array}$ \\
\hline Acetazolamide & REV, TFH & $65.71 \% \pm 1.09$ & $3.46 \mu \mathrm{m}$ & ND & ND \\
\hline $\begin{array}{l}\text { Sodium } \\
\text { Stibogluconate }\end{array}$ & ether injection method & $77.0 \pm 0.3$ & $146 \pm 15$ & $-40.3 \pm 0.2$ & ND \\
\hline Vinblastine & thin film hydration method & $99.92 \pm 1.6 \%$ & $234.3 \pm 11.4 \mathrm{~nm}$ & $-34.6 \pm 4.2 \mathrm{mV}$ & $0.24 \pm 0.09$ \\
\hline siRNA & Micro fluidization method & $\begin{array}{l}93.18 \pm 2.10 \\
\%\end{array}$ & $46.30 \pm 0.18$ & $51.48 \pm 2.99$ & $0.19 \pm 0.09$ \\
\hline Tetanus toxoid & $\begin{array}{l}\text { Reverse-phase evaporation } \\
\text { method }\end{array}$ & $42.1 \pm 2.1$ & $2.9 \pm 0.5$ & ND & ND \\
\hline Tenofovir & $\begin{array}{l}\text { Proniosome-derived niosome } \\
\text { method }\end{array}$ & $33.68 \%$ & $50 \mathrm{~nm}$ & $7.7 \mathrm{mV}$ & ND \\
\hline Embelin & Thin-film hydration method & $85.20 \%$ & $500 \mathrm{~nm}$ & ND & 0.121 \\
\hline Ganciclovir & $\begin{array}{l}\text { Reverse-phase evaporation } \\
\text { method }\end{array}$ & $89 \pm 2.13 \%$ & $144 \pm 3.47 \mathrm{~nm}$ & $\begin{array}{l}-9.5 \pm 0.9 \mathrm{mV} \\
\text { to }-27.9 \pm 1.9\end{array}$ & 0.08 \\
\hline Minoxidil & Thin-film hydration method & $69.526 \pm 2.9 \%$ & $\begin{array}{l}0.2 \mu \mathrm{m} \text { to } 1.3 \\
\mu \mathrm{m}\end{array}$ & $\begin{array}{l}-44.71 \pm 1.3 \\
\mathrm{mV}\end{array}$ & $0.244 \pm 0.02$ \\
\hline Nystatin & Thin-film hydration method & $97.88 \pm 1.58$ & $164.8 \pm 22.3 \mathrm{~nm}$ & ND & 0.096 \\
\hline Letrozole & $\begin{array}{l}\text { Reverse-phase evaporation } \\
\text { method }\end{array}$ & $66.60 \%$ & $231.4 \mathrm{~nm}$ & $-8.71 \mathrm{mV}$ & ND \\
\hline
\end{tabular}




\begin{tabular}{|l|l|l|l|l|l|}
\hline Diallyl disulfide & Sonication method & $68.6 \pm 3.3$ & $140 \pm 30 \mathrm{~nm}$ & $\begin{array}{l}-30.67 \pm 0.45 \\
\mathrm{mV}\end{array}$ & $\mathrm{ND}$ \\
\hline $\begin{array}{l}\text { Morin hydrate } \\
\text { (MH) }\end{array}$ & Thin-film hydration method & $98.62 \pm 0.01$ & $109 \pm 0.35 \mathrm{~nm}$ & $\begin{array}{l}-27.48 \pm 3.02 \\
\mathrm{mV}\end{array}$ & $\begin{array}{l}0.096 \pm \\
0.005\end{array}$ \\
\hline Ellagic acid (EA) & $\begin{array}{l}\text { Reverse-phase evaporation } \\
\text { method }\end{array}$ & $38.73 \pm 1.58$ & $312-402 \mathrm{~nm}$ & $\mathrm{ND}$ & $\leq 0.4$ \\
\hline Topotecan & micro fluidization method & $37.50-39.30$ & $128.47 \mathrm{~nm}$ & $-27.00 \mathrm{mV}$ & 0.131 \\
\hline $\begin{array}{l}\text { Hydroxychloroqui } \\
\text { ne }\end{array}$ & hand shaking method & $26.3 \pm 3.98 \%$ & $\begin{array}{l}4.16 \pm 0.03 \\
\mu \mathrm{m}\end{array}$ & $\mathrm{ND}$ & $\mathrm{ND}$ \\
\hline Glucocorticoid & Thin-film hydration method & $77.0 \pm 0.3$ & $186 \pm 24 \mathrm{~nm}$ & $\begin{array}{l}-25.1 \pm 0.1 \\
\mathrm{mV}\end{array}$ & $\mathrm{ND}$ \\
\hline Gemifloxacin & solvent injection method & $64.9 \pm 0.66 \%$ & $213.2 \pm 1.5 \mathrm{~nm}$ & $\begin{array}{l}-34.7 \pm 2.2 \\
\mathrm{mV}\end{array}$ & ND \\
\hline Doxorubicin & Thin-film hydration method & $75 \pm 1.22$ & $338 \pm 3.14 \mathrm{~nm}$ & $\begin{array}{l}-23.7 \pm 0.39 \\
\mathrm{mV}\end{array}$ & $0.17 \pm 0.09$ \\
\hline
\end{tabular}

ND: Not determined. 


\section{Application of in-silico methods in niosome preparation}

\subsection{Molecular dynamic simulation}

The design of in-silico drug delivery formulation requires a molecular dynamic simulation (MDS) tool, which predicts formulation features prior to synthesis and provides information about possible self-assembled structures; therefore, in vitro and in vivo experiments are required less [104, 105]. MDSs are appropriate for the examination of atomic-level intermolecular interactions, responsible for the determination of diffusivity, solubility, carrier-drug miscibility, drug accumulation in organs, cell distribution, clearance, kidney filtration, and the kinetics of drug release that affects niosomes [106]. A significant cause of drug failure in clinical trials is poor bioavailability due to ineffective cell membrane penetration [107]. Operated broadly MDS estimates the nanocarrier-loaded drug permeation to a cell membrane [108], also it is a dependable technique that has been implemented for the analysis of interactions and the orientations of drug molecules and bilayer forms [109].

Solubility is the first important step in the absorption of drug from bilayer structures to the target [110]. The application of a multitude of reactions in the solvent media is necessary in the process of niosome manufacture. On the other hand, the solvent can affect the reaction kinetics, purity, and production of operations such as crystallization and extraction. [111]. thus, in the pharmaceutical industry solubility is a key factor to select the appropriate solvent. Nowadays, computational prediction of solubility requires molecular surface area assessments, hydrophilicity/hydrophobicity calculations, electronic and topological evaluations [112]. A comprehensive perception of drugnanocarriers solubility alterations by changing the $\mathrm{pH}$ and salt concentration in the variety of organs can be achieved from MDS. In the event of moderately soluble or insoluble drugs, multiple applied carrier molecules are responsible for improving the stability of the drug [113, 114]. To calculate the miscibility of pharmaceuticals and carriers compounds, a computational model, is developed [115, 116]. One of the MDS aspects is drug loading and releasing evaluation [117, 118]. The simulations showed that the changes in drug load cause the nanocarrier structure to change significantly. The size, internal structure, and location of the drug in the nanocarriers are also vital issues in terms of drug release $[119,120]$. Free energy calculations can play a significant role in the placement of drug components in the nanocarriers and their release process. In many cases, nanocarriers are designed and simulated to release the evaluation of their drugs in response to $\mathrm{pH}$ changes [121, 122]. Kinetics is one of the necessary physicochemical descriptors that represent the association and dissociation rates of a binding or non-binding ligand to its target by MDS methods [123]. NMR and X-ray crystallographic structures often indicate ligand-binding pockets; however, experimental models sometimes hide other potentially druggable sites because most proteins have small-molecule binding pockets that are not simply identified [124]. These cryptic [125] and allosteric [126] binding sites require a conformational alteration to become visible. A significant aspect of drugs is their capability to crystallize in various structures or polymorphs. Each polymorph of the medicine may vary from others in physio-chemical features, for instance (density, solubility, bioavailability, mechanical strength, dissolution rate, and alike) that can affect fabrication and the therapeutic performance, so the crystallization of complex drug crystals and the chance of new polymorphs of the crystal structure can be studied by MDS [127-129].

To date, full reports of all MDS niosome studies are represented. The first report of a niosomal bilayer was represented by Sanghwa et al. [130]. In a period of 60 nanoseconds, MD simulation of span 80 and cholesterol was investigated on multiple physical features such as area per lipid, thickness, number of hydrogen bonds, and diffusion coefficient. Afterward in 2016 Aksornnarong et al. [131] utilized the Span 60 with and without $50 \mathrm{mmol} \%$ cholesterol to form a niosome, based on Gromaces 4.5.4 software in 60ns for each step. At temperature, niosome properties including area per lipid, molecular orientation, membrane thickness, lateral and transversal diffusion, and number and dynamics of hydrogen bonds with or without cholesterol were calculated from the dynamic 
simulation. The dynamic simulation represented, as the niosome without cholesterol prefers, gel phase formation with a higher order structure; however, with cholesterol, the niosome indicated more fluidity and a less ordered structure. Yoochan et al. [132] simulated the interaction between the Span 60/cholesterol niosome with flavones using the Gromacs software package (version 4.5.2). At a high concentration, it was aggregated at the center of the niosome and increased membrane thickness, but at a low concentration, flavone crossed the bilayer. After that in 2018, $i$ [133] used molecular dynamics simulations to represent the dynamical properties and structure of niosome formed by Span 60 and cholesterol molecules at various cholesterol concentrations (from $0 \mathrm{~mol} \%$ to $70 \mathrm{~mol} \%$ ). They investigated whether cholesterol influences the structure of the niosome and its characteristics, including compressibility, area per molecule, and thickness. Finally, in 2019, Barani et al. [134] Demonstrated the dynamic features of Span 60 / Teen 60 / cholesterol and Span 60 / Teen 60 / ergosterol using the Gromacs software (version 4.5.4) of MD simulation. They also suggested the formulation of DNA loaded with niosomes compressed with protamine and $\mathrm{Fe} 3 \mathrm{O} 4$ nanoparticles with ergosterol instead of cholesterol. The purpose of designing drug delivery systems is to predict formulations that have advantages such as high trapping efficiency and low cytotoxicity., reduce frequency of drug consumption, and magnetic features for targeted delivery.

\subsection{ADME properties}

The pharmacokinetic knowledge of ADME is a crucial part of the drug delivery system study; on the other hand, achieving any therapeutic goal with a new drug delivery system from the early stages to the final clinical evaluations requires absorption, distribution, metabolism and excretion (ADME) [135, 136] (Figure 10). To check the absorption: Caco-2 permeability, human intestinal absorption, bioavailability of F (20\% and 30\%) bioavailability, Pgp-inhibitor, and Pgp substrate are calculated. Plasma protein binding, Blood-brain barrier, Volume Distribution are assessed for distribution prediction. CYPs are membrane-enzymes that mainly reside in the endoplasmic reticulum and mitochondria of hepatocytes and the intestines. CYPs (CYPs 3A4, 2D6, 2C19, 2C9, and 1A2) are in charge of the metabolism of more than $80 \%$ of clinically used drugs [137]. Clearance and T1 / 2 (halflife) are investigated to determine exertion. In addition, toxicity is mostly evaluated by hERG blockers and human Hepatotoxicity $[138,139]$. The absorption of biomolecules changes by alteration of hydrophobicity $(\log \mathrm{P})$, solubility $(\log S)$, polarity, the shape of the molecule, ionization, and molecular weight as well as size. Metabolism and excretion are also influenced by chemical constructions, and it is necessary to identify chemical groups that are highly exposed to metabolism. For instance, hydrophilic molecules are rapidly eliminated, while lipophilic molecules have a fast metabolism. Many software tools are available to investigate chemical features such as ADMETLAB (http://admet.scbdd.com/calcpre/index/) and SWISS ADME (http://www.swissadme.ch/) [140-143]. 


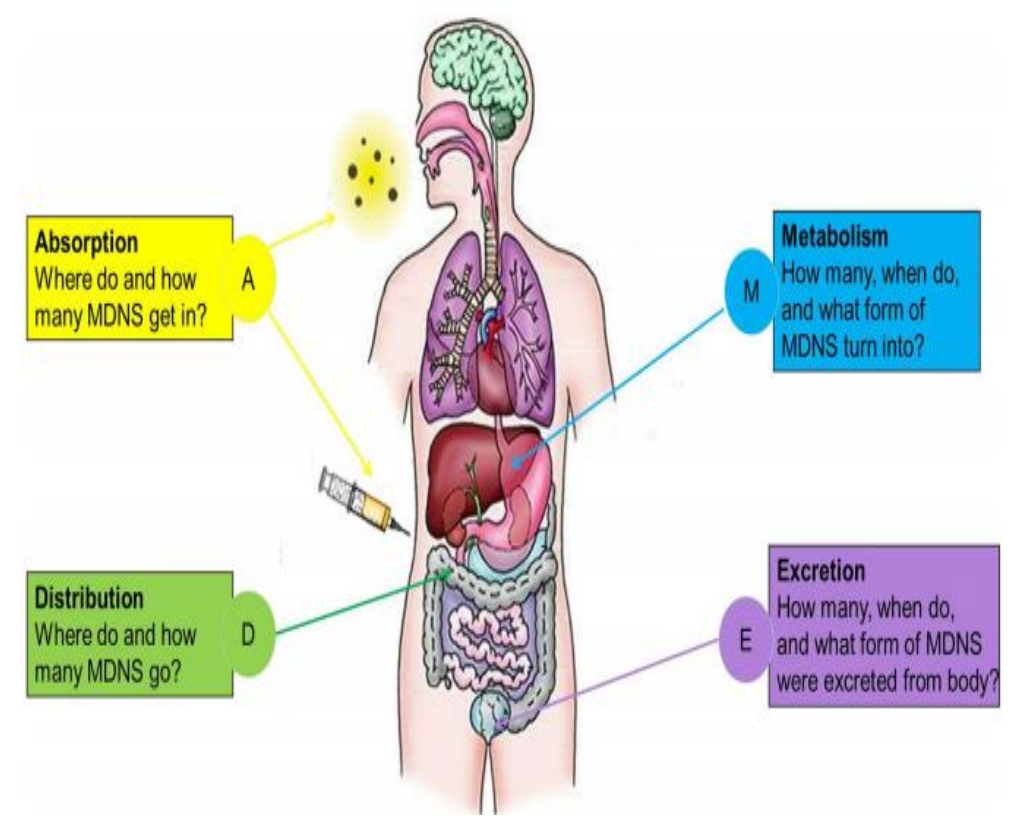

Figure 10. ADME (A: absorption; D, distribution; E, excretion; $M$, metabolism) processes of materials of the drug nanocarrier system (MDNS).

\subsection{Molecular Docking}

Another virtual screening, molecular coupling, mimics biological systems and predicts the interaction of two or more molecular structures (drug and protein or enzyme) together with different binding affinity and RMSD [144]. Among 60 different molecular docking programs, MOE -Dock [145], AutoDock Vina [146], and GOLD [147] have the highest score, furthermore, the appropriate active sites are recognized by GOLD [147] and LeDock [148] and Both Glide (XP) [149] and GOLD identify poses with a $90.0 \%$ efficiency [150]. In Table 5, the molecular coupling of niosomes is represented. Performance prediction can be enhanced by combining in silico methods, for instance: molecular dynamics, molecular coupling, artificial intelligence, and binding free energy (Figure 11)[151]. 


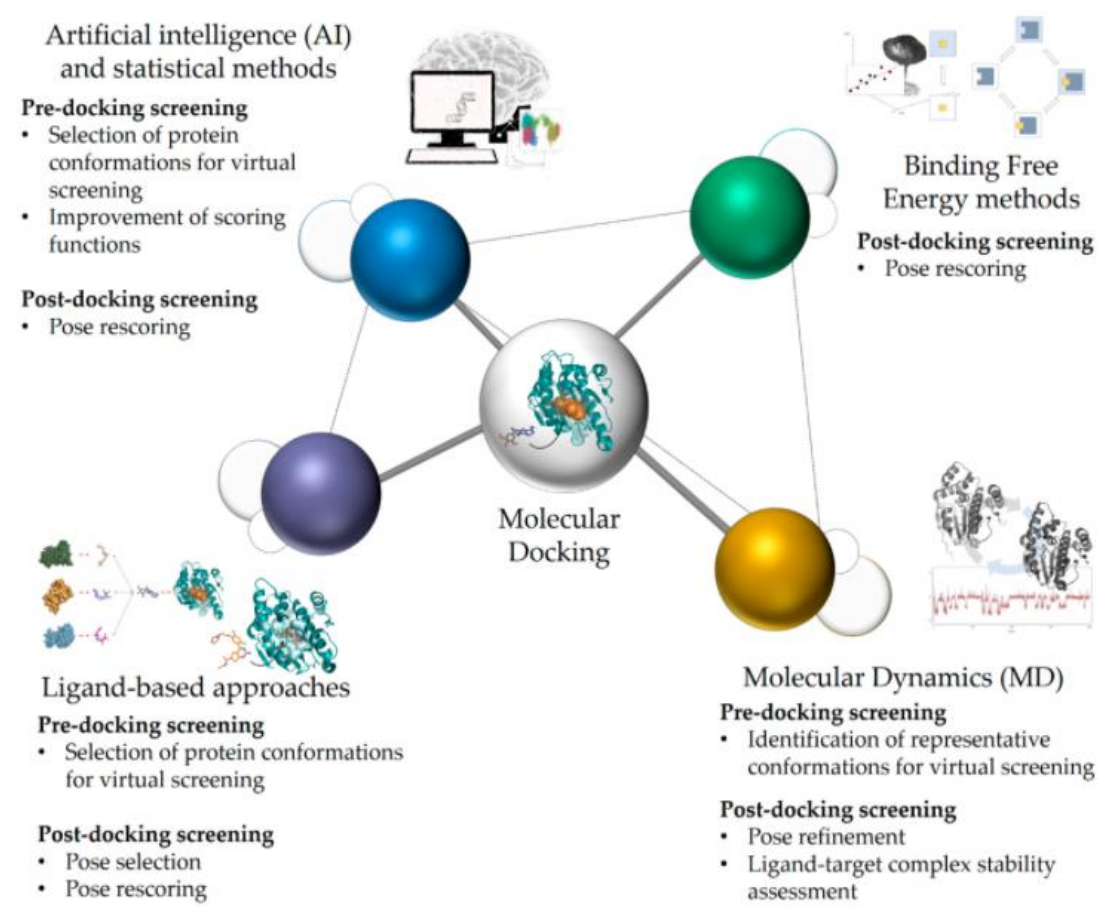

Figure 11. Integration of docking with ligand-based, molecular dynamics, binding free energy approaches, and artificial intelligence.

In summary, in-silico designing and simulations are a significant part of current drug delivery research, providing the possibility of creating a complete pixelated design of the molecular details of the drug and carrier for its user. With this achievement, nanocarriers designing with optimized properties can be done much faster with minimal laboratory effort and cost $[152,153]$. 
Table 5. Molecular coupling of drug-loaded niosomes.

\begin{tabular}{|c|c|c|c|c|c|c|c|}
\hline Gene & $\begin{array}{c}\text { Target gene } \\
\text { PDB ID }\end{array}$ & $\begin{array}{l}\text { Niosome } \\
\text { Material }\end{array}$ & $\begin{array}{c}\text { Computational } \\
\text { program }\end{array}$ & Disease & Ligand & $\begin{array}{l}\text { Active sites } \\
\text { Interaction }\end{array}$ & Ref. \\
\hline MMP-2 & $1 \mathrm{CK} 7$ & \multirow[t]{2}{*}{$\begin{array}{l}\text { Span60 and } \\
\text { cholesterol }\end{array}$} & \multirow[t]{2}{*}{ AutoDock 4.0} & \multirow{2}{*}{$\begin{array}{l}\text { tumor milieu in } \\
\text { pancreatic cancer, } \\
\text { colorectal cancer, } \\
\text { ovarian cancer, and } \\
\text { breast cancer, etc }\end{array}$} & \multirow[t]{2}{*}{$\begin{array}{c}\text { Morusin } \\
\text { (anticancer) }\end{array}$} & $\begin{array}{l}\text { 1: Polar interaction between Asn 111, Asn 55, } \\
\text { and His } 193 \text { with morusin } \\
\text { 2: cationic-pi interactions between Tyr } 182 \\
\text { MMP-9 and morusin } \\
\text { 3:hydrophobic interactions between Pro } 105 \\
\quad \text { and Leu } 190 \text { with morusin }\end{array}$ & \multirow{2}{*}{ [154] } \\
\hline MMP-9 & $1 \mathrm{GKC}$ & & & & & $\begin{array}{l}\text { 1: Hydrogen bond between Tyr } 393 \text { MMP-9 } \\
\text { and morusin } \\
\text { 2: cationic-pi interactions between Tyr } 423 \\
\text { MMP-9 and morusin } \\
\text { 3: hydrophobic interactions between Leu 187, } \\
\text { Met 422, and His } 401 \text { with morusin }\end{array}$ & \\
\hline $\begin{array}{l}\text { Human serum } \\
\text { albumin } \\
\text { (HSA) }\end{array}$ & $1 \mathrm{BMO}$ & \multirow{2}{*}{$\begin{array}{l}\text { No } \\
\text { information. }\end{array}$} & \multirow{2}{*}{ AutoDock 4.2.2 } & $\begin{array}{l}\text { nosocomial infections of } \\
\text { P. aeruginosa, E. coli. } \\
\text { k. pneumonia, S. typhi, }\end{array}$ & $\begin{array}{l}\text { Ho (III) }\left[\mathrm{Ho}\left(2,2^{\prime}-\right.\right. \\
\text { bipyridine) }(\mathrm{H} 2 \mathrm{O}) 6] \\
\mathrm{Cl} 3\end{array}$ & $\begin{array}{l}\text { Interaction with Ho (III) ASN18, ALA21, } \\
\text { LEU135, LEU139, LEU155 and ALA158 of } \\
\text { HSA }\end{array}$ & \multirow[t]{2}{*}{ [155] } \\
\hline $\begin{array}{l}\text { bovine serum } \\
\text { albumin (BSA) }\end{array}$ & $3 \mathrm{~V} 03$ & & & $\begin{array}{l}\text { E. VRE, Acinetobacter, } \\
\text { E. faecium, MRSA, and } \\
\text { faecalis. }\end{array}$ & $\begin{array}{c}\text { (Antimicrobial and } \\
\text { antitumor) }\end{array}$ & $\begin{array}{l}\text { Interaction with the hydrophobic residues } \\
\text { LEU24, PHE36, VAL40, and TRP134 of Ho } \\
\text { (III) of BSA }\end{array}$ & \\
\hline
\end{tabular}




\begin{tabular}{|c|c|c|c|c|c|c|c|}
\hline $\begin{array}{l}\text { d(CGCGAATT } \\
\text { CGCG)2 } \\
\text { sequence } \\
\text { dodecamer } \\
\text { DNA }\end{array}$ & 1BNA & & & $\begin{array}{l}\text { and human lung } \\
\text { carcinoma and breast } \\
\text { cancer cell lines. }\end{array}$ & & $\begin{array}{l}\text { 1: the gap between the DNA minor grooves } \\
\text { and bipyridine ring. } \\
\text { 2: } 5.31 \mathrm{kcal} \text { mol - } 1 \text { binding energy between } \\
\text { the DNA minor groove and Ho(III) }\end{array}$ & \\
\hline $\begin{array}{c}\text { concanavallinA } \\
(\text { CON A })\end{array}$ & $5 \mathrm{CNA}$ & $\begin{array}{l}\text { Span 60, } \\
\text { Tween } 80 \\
\text { and } \\
\text { cholesterol }\end{array}$ & $\begin{array}{c}\text { Maestro } \\
\text { Schrodinger }\end{array}$ & $\begin{array}{l}\text { In tumor tissue } \\
\text { including skin, lung, } \\
\text { breast, prostate, } \\
\text { melanoma, and gastric } \\
\text { overexpression of } \\
\text { glucose transporters. }\end{array}$ & $\begin{array}{c}\text { N- lauryl } \\
\text { glucosamine (NLG) } \\
\text { (Target } \\
\text { ligand/penetration } \\
\text { enhancer) } \\
\text { and N-acetyl } \\
\text { glucosamine (NAG) } \\
\text { anchored } \\
\text { doxorubicin (DOX) } \\
\text { (anticancer) }\end{array}$ & $\begin{array}{c}\text { The hydrophobic interaction of TYR } 100 \text { and } \\
\text { ALA } 207 \text { with either C3, C4, C5, or C6 atoms } \\
\text { of D-mannose of conA }\end{array}$ & [156] \\
\hline $\begin{array}{c}\text { HSV-1 } \\
\text { thymidine } \\
\text { kinase proteins }\end{array}$ & $\begin{array}{l}1 \mathrm{KI} 7,1 \mathrm{KI} 4 \\
1 \mathrm{KIM}, 1 \mathrm{E} 2 \mathrm{P}\end{array}$ & $\begin{array}{c}\text { Cholesterol, } \\
\text { non-ionic } \\
\text { surfactant } \\
\text { (Brij } 93 \text { or } \\
\text { Kolliphor } \\
\text { RH40) and } \\
\text { soy lecithin. }\end{array}$ & $\begin{array}{l}\text { Molecular } \\
\text { Operating } \\
\text { Environment } \\
\quad(\text { MOE } \\
2014.0901)\end{array}$ & $\begin{array}{l}\text { Herpes simplex virus } \\
\text { type } 1(\mathrm{HSV}-1)\end{array}$ & $\begin{array}{l}\text { Curcumin } \\
\text { (antiviral) }\end{array}$ & $\begin{array}{l}\text { 1: In } 1 \mathrm{KI} 7 \mathrm{H}-\text { bond between curcumin and Tyr } \\
\text { 101, interacts via } 2 \mathrm{H} \text {-bonds with the Glu } 225 . \\
\text { 2: In } 1 \mathrm{KIM} \text { curcumin interacts by } 3 \mathrm{H} \text { bonds } \\
\text { with Arg } 176 \text { and Gln } 125 \text {. also interact by H- } \\
\text { bond with the Gln } 125 \text { and Pi-H interaction } \\
\text { with Arg } 163 \text {. } \\
\text { 3: In 1E2P Curcumin interacts with the Tyr } \\
\text { 101, interacts via the H-bond with Gln } 125 . \\
\text { The Pi-H and Pi-Pi interactions between } \mathrm{HOH} \\
2036 \text { and Tyr } 172 \text { residues, respectively. }\end{array}$ & [157] \\
\hline
\end{tabular}

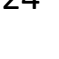




\begin{tabular}{|c|c|c|c|c|c|c|c|}
\hline $\begin{array}{l}\text { bovine serum } \\
\text { albumin (BSA) }\end{array}$ & $3 \mathrm{~V} 03$ & $\begin{array}{l}\text { Span } 60 \text { and } \\
\text { cholesterol }\end{array}$ & Autodock Vina & $\begin{array}{c}\text { Protein modification and } \\
\text { alteration causes such as } \\
\text { diabetes and } \\
\text { Alzheimer's disease. }\end{array}$ & $\begin{array}{c}\text { Carnosine (alanyl-L- } \\
\text { histidine) }\end{array}$ & $\begin{array}{l}\text { H-bonds stabilizing the carnosine-BSA } \\
\text { (Sudlow's site I and II) complex: Arg208, } \\
\text { Gly327 Leu346, and Glu353. }\end{array}$ & {$[158]$} \\
\hline adenosine $\mathrm{A} 2 \mathrm{~A}$ & $3 \mathrm{vg} 9$ & $\begin{array}{l}\text { cholesterol, } \\
\text { nonionic } \\
\text { surfactant } \\
\text { (span60), } \\
\text { soya lecithin }\end{array}$ & Autodock 4.2.6 & Migraine & $\begin{array}{c}\text { Caffeine } \\
\text { iodine-131-caffeine }\end{array}$ & $\begin{array}{l}\text { same binding affinity of iodine-131-Caffeine } \\
\text { and caffeine with adenosine A2A receptor (- } \\
6.49 \mathrm{vs} .-6.50 \mathrm{kcal} / \mathrm{mol}) \text {, respectively. }\end{array}$ & [159] \\
\hline
\end{tabular}




\section{Conclusions}

Niosomes are a relatively recent drug delivery system whose structure consists of two layers of nonionic surfactants. By changing the experiment conditions and the ratio of surfactant and cholesterol used, different drugs can be loaded in niosomes. In addition, because of their amphipathic nature, hydrophobic and hydrophilic drugs can be loaded into the niosomes. Niosomes also increase drug stability, slow drug release, and reduce drug toxicity. Compared to other drug delivery systems, niosomes do not require specific conditions for preparation and storage. Due to recent developments in computational optimization as well as new theoretical advances, in the future, in-silico tools can play a significant role in the field of drug delivery. In summary, it seems that with more studies, we can expect a good market for niosomes in pharmaceutical biotechnology in the future.

\section{Declarations}

- Acknowledgements: None

- Availability of Data and Materials: N/A

- Conflict of Interest: None

- Funding: None

- Informed Consent: N/A

- Research involvement of Human or animals: N/A 


\section{References}

1. Moghimi, S.M. and T.J.A.d.d.r. Kissel, Particulate nanomedicines. 2006. 58(14): p. 14511455 .

2. Miller, R.P., et al., Mechanisms of cisplatin nephrotoxicity. 2010. 2(11): p. 2490-2518.

3. Grigorian, A., C.B.J.J.o.c. O'Brien, and t. hepatology, Hepatotoxicity secondary to chemotherapy. 2014. 2(2): p. 95.

4. Omoti, A.E. and C.E.J.P.p. Omoti, Ocular toxicity of systemic anticancer chemotherapy. 2006. 4(2): p. 55.

5. Lindenberg, M., et al., Classification of orally administered drugs on the World Health Organization Model list of Essential Medicines according to the biopharmaceutics classification system. 2004. 58(2): p. 265-278.

6. Hauss, D.J., Oral lipid-based formulations: enhancing the bioavailability of poorly watersoluble drugs. Vol. 170. 2007: CRC Press.

7. Barani, M., et al., A new formulation of hydrophobin-coated niosome as a drug carrier to cancer cells. Materials Science and Engineering: C, 2020. 113: p. 110975.

8. Choi, Y.H. and H.-K.J.J.o.p.i. Han, Nanomedicines: current status and future perspectives in aspect of drug delivery and pharmacokinetics. 2018. 48(1): p. 43-60.

9. Rajaee Behbahani, S., et al., Red elemental selenium nanoparticles mediated substantial variations in growth, tissue differentiation, metabolism, gene transcription, epigenetic cytosine DNA methylation, and callogenesis in bittermelon (Momordica charantia); an in vitro experiment. PloS one, 2020. 15(7): p. e0235556.

10. Sotoodehnia-Korani, S., et al., Selenium nanoparticles induced variations in growth, morphology, anatomy, biochemistry, gene expression, and epigenetic DNA methylation in Capsicum annuum; an in vitro study. Environmental Pollution, 2020. 265: p. 114727.

11. Mahale, N., et al., Niosomes: novel sustained release nonionic stable vesicular systems-an overview. Advances in colloid and interface science, 2012. 183: p. 46-54.

12. Rai, A., et al., Niosomes: An approach to current drug delivery-A Review. International Journal of Advances in Pharmaceutics, 2017. 6(2): p. 41-48.

13. Moghanloo, M., et al., Differential physiology and expression of phenylalanine ammonia lyase (PAL) and universal stress protein (USP) in the endangered species Astragalus fridae following seed priming with cold plasma and manipulation of culture medium with silica nanoparticles. 3 Biotech, 2019. 9(7): p. 1-13.

14. Akbarzadeh, I., et al., Optimization, physicochemical characterization, and antimicrobial activity of a novel simvastatin nano-niosomal gel against E. coli and S. aureus. 2021. 234: p. 105019.

15. Moghanloo, M., et al., Seed priming with cold plasma and supplementation of culture medium with silicon nanoparticle modified growth, physiology, and anatomy in Astragalus fridae as an endangered species. Acta Physiologiae Plantarum, 2019. 41(4): p. 1-13.

16. Manosroi, A., et al., Entrapment enhancement of peptide drugs in niosomes. 2010. 27(3): p. 272-280. 
17. Muller, J.M., et al., VIP as a cell-growth and differentiation neuromodulator role in neurodevelopment. Mol Neurobiol, 1995. 10(2-3): p. 115-34.

18. Kumar, G.P. and P. Rajeshwarrao, Nonionic surfactant vesicular systems for effective drug delivery - an overview. Acta pharmaceutica sinica B, 2011. 1(4): p. 208-219.

19. Weng, Y., et al., Nanotechnology-based strategies for treatment of ocular disease. Acta Pharm Sin B, 2017. 7(3): p. 281-291.

20. Akbarzadeh, I., et al., Niosomal formulation for co-administration of hydrophobic anticancer drugs into MCF-7 cancer cells. 2020. 11(2).

21. Ghafelehbashi, R., et al., Preparation, physicochemical properties, in vitro evaluation and release behavior of cephalexin-loaded niosomes. 2019. 569: p. 118580.

22. Hedayati Ch, M., et al., Niosome-encapsulated tobramycin reduced antibiotic resistance and enhanced antibacterial activity against multidrug-resistant clinical strains of Pseudomonas aeruginosa. 2021. 109(6): p. 966-980.

23. Akbarzadeh, I., et al., Preparation, Optimization and In-Vitro Evaluation of CurcuminLoaded Niosome@ calcium alginatenanocarrier as a new approach for breast cancer treatment. 2021. 10(3): p. 173.

24. Akbarzadeh, I., et al., Optimized doxycycline-loaded niosomal formulation for treatment of infection-associated prostate cancer: An in-vitro investigation. 2020. 57: p. 101715.

25. Moghaddam, F.D., et al., Delivery of melittin-loaded niosomes for breast cancer treatment: an in vitro and in vivo evaluation of anti-cancer effect. 2021. 12(1): p. 1-35.

26. Khanam, N., et al., Recent trends in drug delivery by niosomes: a review. Asian journal of pharmaceutical research and development, 2013: p. 115-122.

27. De, A., et al., Smart niosomes of temozolomide for enhancement of brain targeting. 2018. 5: p. 1849543518805355.

28. Sadeghi, S., et al., Design and physicochemical characterization of lysozyme loaded niosomal formulations as a new controlled delivery system. 2020. 53(10): p. 921-930.

29. Seddighinia, F.S., et al., Seed-priming with cold plasma and supplementation of nutrient solution with carbon nanotube enhanced carotenoid contents and the expression of psy and pds in Bitter melon (Momordica charantia). JOURNAL OF APPLIED BOTANY AND FOOD QUALITY, 2021. 94: p. 7-14.

30. Kazi, K.M., et al., Niosome: a future of targeted drug delivery systems. Journal of advanced pharmaceutical technology \& research, 2010. 1(4): p. 374.

31. Targhi, A.A., et al., Synergistic effect of curcumin-Cu and curcumin-Ag nanoparticle loaded niosome: Enhanced antibacterial and anti-biofilm activities. 2021. 115: p. 105116.

32. Moghtaderi, M., et al., Enhanced Antibacterial Activity of Echinacea angustifolia Extract against Multidrug-Resistant Klebsiella pneumoniae through Niosome Encapsulation. 2021. 11(6): p. 1573.

33. Onoue, S., S. Yamada, and H.-K.J.I.j.o.n. Chan, Nanodrugs: pharmacokinetics and safety. 2014. 9: p. 1025. 
34. Baillie, A.J., et al., The preparation and properties of niosomes--non-ionic surfactant vesicles. J Pharm Pharmacol, 1985. 37(12): p. 863-8.

35. Din, F.U. and S.U. Shah, Proniosomes derived niosomes: recent advancements in drug delivery and targeting. Drug Delivery, 2017. 24.

36. Akbarzadeh, I., et al., Niosomal delivery of simvastatin to MDA-MB-231 cancer cells. 2020. 46(9): p. 1535-1549.

37. Naseroleslami, M., et al., Simvastatin-loaded nano-niosomes confer cardioprotection against myocardial ischemia/reperfusion injury. 2021: p. 1-10.

38. Moghassemi, S. and A. Hadjizadeh, Nano-niosomes as nanoscale drug delivery systems: an illustrated review. J Control Release, 2014. 185: p. 22-36.

39. Shi, C., et al., A drug-specific nanocarrier design for efficient anticancer therapy. Nature communications, 2015. 6(1): p. 1-14.

40. Mirzaie, A., et al., Preparation and optimization of ciprofloxacin encapsulated niosomes: A new approach for enhanced antibacterial activity, biofilm inhibition and reduced antibiotic resistance in ciprofloxacin-resistant methicillin-resistance Staphylococcus aureus. 2020. 103: p. 104231.

41. Iranbakhsh, A., Z.O. Ardebili, and N.O. Ardebili, Synthesis and characterization of zinc oxide nanoparticles and their impact on plants. Plant Responses to Nanomaterials: Recent Interventions, and Physiological and Biochemical Responses, 2021: p. 33-93.

42. Khan, R. and R.J.J.o.p.i. Irchhaiya, Niosomes: a potential tool for novel drug delivery. 2016. 46(3): p. 195-204.

43. Ge, X., et al., Advances of non-ionic surfactant vesicles (niosomes) and their application in drug delivery. 2019. 11(2): p. 55.

44. Marianecci, C., et al., Niosomes from 80s to present: the state of the art. Adv Colloid Interface Sci, 2014. 205: p. 187-206.

45. Jiao, J., Polyoxyethylated nonionic surfactants and their applications in topical ocular drug delivery. Adv Drug Deliv Rev, 2008. 60(15): p. 1663-73.

46. Biswal, S., et al., Vesicles of non-ionic surfactants (niosomes) and drug delivery potential. 2008. 1(1): p. 1-8.

47. Shahiwala, A., A.J.J.o.p. Misra, and p. sciences, Studies in topical application of niosomally entrapped nimesulide. 2002. 5(3): p. 220-225.

48. Pardakhty, A., J. Varshosaz, and A.J.I.j.o.p. Rouholamini, In vitro study of polyoxyethylene alkyl ether niosomes for delivery of insulin. 2007. 328(2): p. 130-141.

49. Mohanty, A. and J.J.J.o.C.A. Dey, Enantioselectivity of vesicle-forming chiral surfactants in capillary electrophoresis: Role of the surfactant headgroup structure. 2006. 1128(1-2): p. 259-266.

50. Harvey, R.D., et al., The effect of electrolyte on the morphology of vesicles composed of the dialkyl polyoxyethylene ether surfactant 2C18E12. Chem Phys Lipids, 2005. 133(1): p. 27-36.

51. Puras, G., et al., A novel cationic niosome formulation for gene delivery to the retina. 2014. 174: p. 27-36. 
52. Primavera, R., et al., An insight of in vitro transport of PEGylated non-ionic surfactant vesicles (NSVs) across the intestinal polarized enterocyte monolayers. 2018. 127: p. 432-442.

53. Barani, M., et al., Lawsone-loaded Niosome and its antitumor activity in MCF-7 breast Cancer cell line: a Nano-herbal treatment for Cancer. 2018. 26(1): p. 11-17.

54. Bhaskaran, S. and L.J.I.j.o.p.s. Panigrahi, Formulation and evaluation of niosomes using different non-ionic surfactants. 2002. 64(1): p. 63.

55. Rogerson, A., et al., The distribution of doxorubicin in mice following administration in niosomes. J Pharm Pharmacol, 1988. 40(5): p. 337-42.

56. Sahu, A.K., J. Mishra, and A.K.J.S.m. Mishra, Introducing Tween-curcumin niosomes: Preparation, characterization and microenvironment study. 2020. 16(7): p. 1779-1791.

57. Uchegbu, I.F., A.T.J.A.i.c. Florence, and i. science, Non-ionic surfactant vesicles (niosomes): physical and pharmaceutical chemistry. 1995. 58(1): p. 1-55.

58. Yoshioka, T., B. Sternberg, and A.T.J.I.j.o.p. Florence, Preparation and properties of vesicles (niosomes) of sorbitan monoesters (Span 20, 40, 60 and 80) and a sorbitan triester (Span 85). 1994. 105(1): p. 1-6.

59. Mokhtar, M., et al., Effect of some formulation parameters on flurbiprofen encapsulation and release rates of niosomes prepared from proniosomes. 2008. 361(1-2): p. 104-111.

60. Obeid, M.A., et al., The effects of hydration media on the characteristics of non-ionic surfactant vesicles (NISV) prepared by microfluidics. 2017. 516(1-2): p. 52-60.

61. Sahin, N.O.J.N. and n.f.b. applications, Niosomes as nanocarrier systems. 2007: p. 67-81.

62. Marianecci, C., et al., Non-ionic surfactant vesicles in pulmonary glucocorticoid delivery: characterization and interaction with human lung fibroblasts. 2010. 147(1): p. 127-135.

63. Mizrahy, S., et al., Hyaluronan-coated nanoparticles: the influence of the molecular weight on CD44-hyaluronan interactions and on the immune response. 2011. 156(2): p. 231-238.

64. Liu, T., et al., Structure behaviors of hemoglobin in PEG 6000/Tween 80/Span 80/H2O niosome system. 2007. 293(1-3): p. 255-261.

65. Pouyani, T. and G.D.J.B.c. Prestwich, Functionalized derivatives of hyaluronic acid oligosaccharides: drug carriers and novel biomaterials. 1994. 5(4): p. 339-347.

66. Kaur, D., S.J.J.o.d.d. Kumar, and therapeutics, Niosomes: present scenario and future aspects. 2018. 8(5): p. 35-43.

67. Ong, S.G.M., et al., Evaluation of extrusion technique for nanosizing liposomes. 2016. 8(4): p. 36.

68. Jain, S., et al., Mannosylated niosomes as adjuvant-carrier system for oral genetic immunization against hepatitis B. Immunol Lett, 2005. 101(1): p. 41-9.

69. Devaraj, G.N., et al., Release studies on niosomes containing fatty alcohols as bilayer stabilizers instead of cholesterol. 2002. 251(2): p. 360-365.

70. Baillie, A., et al., The preparation and properties of niosomes-non-ionic surfactant vesicles. 1985. 37(12): p. 863-868. 
71. Khan, D.H., et al., Process optimization of ecological probe sonication technique for production of rifampicin loaded niosomes. Journal of Drug Delivery Science and Technology, 2019. 50: p. 27-33.

72. Chen, S., et al., Recent advances in non-ionic surfactant vesicles (niosomes): Fabrication, characterization, pharmaceutical and cosmetic applications. Eur J Pharm Biopharm, 2019. 144: p. 18-39.

73. Baillie, A.J., et al., Non-ionic surfactant vesicles, niosomes, as a delivery system for the antileishmanial drug, sodium stibogluconate. J Pharm Pharmacol, 1986. 38(7): p. 502-5.

74. Guinedi, A.S., et al., Preparation and evaluation of reverse-phase evaporation and multilamellar niosomes as ophthalmic carriers of acetazolamide. Int J Pharm, 2005. 306(1-2): p. 7182.

75. Rai, A.K., et al., Niosomes: An approach to current drug delivery-A Review. 2017. 6(2): p. 41-48.

76. Obeid, M.A., et al., Formulation of Nonionic Surfactant Vesicles (NISV) Prepared by Microfluidics for Therapeutic Delivery of siRNA into Cancer Cells. Mol Pharm, 2017. 14(7): p. 24502458 .

77. Chen, S., et al., Recent advances in non-ionic surfactant vesicles (niosomes): Fabrication, characterization, pharmaceutical and cosmetic applications. European Journal of Pharmaceutics and Biopharmaceutics, 2019. 144: p. 18-39.

78. Yeo, L.K., et al., Brief effect of a small hydrophobic drug (cinnarizine) on the physicochemical characterisation of niosomes produced by thin-film hydration and microfluidic methods. 2018. 10(4): p. 185.

79. Bhaskaran, S., P.J.A.P. Lakshmi, aceutica Sciencia., and 27, Comparative evaluation of niosome formulations prepared by different techniques. 2009. 32.

80. Azmin, M., et al., The effect of non-ionic surfactant vesicle (niosome) entrapment on the absorption and distribution of methotrexate in mice. 1985. 37(4): p. 237-242.

81. Sezgin-Bayindir, Z., et al., Niosomes encapsulating paclitaxel for oral bioavailability enhancement: preparation, characterization, pharmacokinetics and biodistribution. 2013. 30(8): p. 796-804.

82. Amiri, B., et al., Delivery of vinblastine-containing niosomes results in potent in vitro/in vivo cytotoxicity on tumor cells. 2018. 44(8): p. 1371-1376.

83. Katare, R., et al., Development of polysaccharide-capped niosomes for oral immunization of tetanus toxoid. 2006. 16(3): p. 167-172.

84. Zidan, A.S. and M.J.J.J.o.p.s. Habib, Maximized mucoadhesion and skin permeation of antiAIDS-loaded niosomal gels. 2014. 103(3): p. 952-964.

85. Alam, M.S., et al., Embelin-loaded oral niosomes ameliorate streptozotocin-induced diabetes in Wistar rats. Biomed Pharmacother, 2018. 97: p. 1514-1520.

86. Akhter, S., et al., Development and evaluation of nanosized niosomal dispersion for oral delivery of Ganciclovir. Drug Dev Ind Pharm, 2012. 38(1): p. 84-92.

87. Balakrishnan, P., et al., Formulation and in vitro assessment of minoxidil niosomes for enhanced skin delivery. Int J Pharm, 2009. 377(1-2): p. 1-8. 
88. El-Ridy, M.S., et al., Niosomes as a potential drug delivery system for increasing the efficacy and safety of nystatin. Drug Dev Ind Pharm, 2011. 37(12): p. 1491-508.

89. Alam, M., et al., Development, characterization and efficacy of niosomal diallyl disulfide in treatment of disseminated murine candidiasis. Nanomedicine, 2013. 9(2): p. 247-56.

90. Waddad, A.Y., et al., Formulation, characterization and pharmacokinetics of Morin hydrate niosomes prepared from various non-ionic surfactants. Int J Pharm, 2013. 456(2): p. 446-58.

91. Junyaprasert, V.B., P. Singhsa, and A.J.a.j.o.p.s. Jintapattanakit, Influence of chemical penetration enhancers on skin permeability of ellagic acid-loaded niosomes. 2013. 8(2): p. 110-117.

92. Ag Seleci, D., et al., Rapid microfluidic preparation of niosomes for targeted drug delivery. 2019. 20(19): p. 4696.

93. Zubairu, Y., et al., Design and development of novel bioadhesive niosomal formulation for the transcorneal delivery of anti-infective agent: In-vitro and ex-vivo investigations. 2015. 10(4): p. 322330 .

94. Shilpa, S., B. Srinivasan, and M.J.I.J.o.D.D. Chauhan, Niosomes as vesicular carriers for delivery of proteins and biologicals. 2011. 3(1).

95. Escudero, I., et al., Formulation and characterization of Tween 80/cholestherol niosomes modified with tri-n-octylmethylammonium chloride (TOMAC) for carboxylic acids entrapment. 2014. 461: p. 167-177.

96. Manosroi, A., et al., Characterization of vesicles prepared with various non-ionic surfactants mixed with cholesterol. 2003. 30(1-2): p. 129-138.

97. Uchegbu, I.F. and S.P.J.I.j.o.p. Vyas, Non-ionic surfactant based vesicles (niosomes) in drug delivery. 1998. 172(1-2): p. 33-70.

98. Girigoswami, A., S. Das, and S. De, Fluorescence and dynamic light scattering studies of niosomes-membrane mimetic systems. Spectrochim Acta A Mol Biomol Spectrosc, 2006. 64(4): p. 859-66.

99. Abd-Elbary, A., H. El-Laithy, and M.J.I.j.o.p. Tadros, Sucrose stearate-based proniosomederived niosomes for the nebulisable delivery of cromolyn sodium. 2008. 357(1-2): p. 189-198.

100. Patel, J., et al., Potentiating antimicrobial efficacy of propolis through niosomal-based system for administration. 2015. 4(2): p. 94-101.

101. Bayindir, Z.S. and N. Yuksel, Characterization of niosomes prepared with various nonionic surfactants for paclitaxel oral delivery. J Pharm Sci, 2010. 99(4): p. 2049-60.

102. Abdel-Mageed, H.M., et al., Development of novel flexible sugar ester vesicles as carrier systems for the antioxidant enzyme catalase for wound healing applications. 2012. 47(7): p. 11551162.

103. El-Menshawe, S.J.J.o.d.d.s. and technology, A novel approach to topical acetazolamide/PEG 400 ocular niosomes. 2012. 22(4): p. 295-299.

104. Katiyar, R.S. and P.K. Jha, Molecular simulations in drug delivery: Opportunities and challenges. Wiley Interdisciplinary Reviews: Computational Molecular Science, 2018. 8(4): p. e1358. 
105. Li, Q., et al., Drug-loaded pH-responsive polymeric micelles: Simulations and experiments of micelle formation, drug loading and drug release. Colloids and Surfaces B: Biointerfaces, 2017. 158: p. 709-716.

106. Xiang, T.-X. and B.D. Anderson, Molecular dynamics simulation of amorphous hydroxypropylmethylcellulose and its mixtures with felodipine and water. Journal of pharmaceutical sciences, 2017. 106(3): p. 803-816.

107. Wen, W., et al., Benzaldehyde, A New Absorption Promoter, Accelerating Absorption on Low Bioavailability Drugs Through Membrane Permeability. Frontiers in pharmacology, 2021. 12: p. 1176.

108. Wadhwa, R., et al., Molecular dynamics simulations and experimental studies reveal differential permeability of withaferin-A and withanone across the model cell membrane. Scientific reports, 2021. 11(1): p. 1-15.

109. Yousefpour, A., et al., Interaction of PEGylated anti-hypertensive drugs, amlodipine, atenolol and lisinopril with lipid bilayer membrane: a molecular dynamics simulation study. Biochimica et Biophysica Acta (BBA)-Biomembranes, 2015. 1848(8): p. 1687-1698.

110. Gao, Y. and K.W. Olsen, Molecular dynamics of drug crystal dissolution: simulation of acetaminophen form I in water. Molecular pharmaceutics, 2013. 10(3): p. 905-917.

111. Gani, R., et al., A modern approach to solvent selection: although chemists' and engineers' intuition is still important, powerful tools are becoming available to reduce the effort needed to select the right solvent. Chemical Engineering, 2006. 113(3): p. 30-44.

112. Seyf, J.Y. and A. Haghtalab, A junction between molecular dynamics simulation and local composition models for computation of solid-liquid equilibrium-A pharmaceutical solubility application. Fluid Phase Equilibria, 2017. 437: p. 83-95.

113. Xiang, T.-X. and B.D. Anderson, Molecular dynamics simulation of amorphous hydroxypropyl-methylcellulose acetate succinate (HPMCAS): polymer model development, water distribution, and plasticization. Molecular pharmaceutics, 2014. 11(7): p. 2400-2411.

114. Hassanvand, A., et al., Biosynthesis of NanoSilver and Its Effect on Key Genes of Flavonoids and Physicochemical Properties of Viola tricolor L. Iranian Journal of Science and Technology, Transactions A: Science, 2021. 45(3): p. 805-819.

115. Gupta, J., et al., Prediction of solubility parameters and miscibility of pharmaceutical compounds by molecular dynamics simulations. The Journal of Physical Chemistry B, 2011. 115(9): p. 2014-2023.

116. Abedi, S., et al., Nitric oxide and selenium nanoparticles confer changes in growth, metabolism, antioxidant machinery, gene expression, and flowering in chicory (Cichorium intybus L.): potential benefits and risk assessment. Environmental Science and Pollution Research, 2021. 28(3): p. 3136-3148.

117. Shariatinia, Z. and A. Mazloom-Jalali, Chitosan nanocomposite drug delivery systems designed for the ifosfamide anticancer drug using molecular dynamics simulations. Journal of Molecular Liquids, 2019. 273: p. 346-367.

118. Moghadam, A.V., et al., New insights into the transcriptional, epigenetic, and physiological responses to zinc oxide nanoparticles in datura stramonium; potential species for phytoremediation. Journal of Plant Growth Regulation, 2021: p. 1-11. 
119. Salo-Ahen, O.M., et al., Molecular Dynamics Simulations in Drug Discovery and Pharmaceutical Development. Processes, 2021. 9(1): p. 71.

120. Soleymanzadeh, R., et al., Selenium nanoparticle protected strawberry against salt stress through modifications in salicylic acid, ion homeostasis, antioxidant machinery, and photosynthesis performance. Acta Biologica Cracoviensia s. Botanica, 2020: p. 33-42-33-42.

121. Rog, T. and A. Bunker, Mechanistic understanding from molecular dynamics simulation in pharmaceutical research 1: drug delivery. Frontiers in Molecular Biosciences, 2020. 7: p. 371.

122. Modi, S. and B.D. Anderson, Determination of drug release kinetics from nanoparticles: overcoming pitfalls of the dynamic dialysis method. Molecular pharmaceutics, 2013. 10(8): p. 30763089.

123. De Vivo, M., et al., Role of molecular dynamics and related methods in drug discovery. Journal of medicinal chemistry, 2016. 59(9): p. 4035-4061.

124. Durrant, J.D. and J.A. McCammon, Molecular dynamics simulations and drug discovery. BMC biology, 2011. 9(1): p. 1-9.

125. Oleinikovas, V., et al., Understanding cryptic pocket formation in protein targets by enhanced sampling simulations. Journal of the American Chemical Society, 2016. 138(43): p. 1425714263.

126. Moghadam, B., et al., Computational evidence of new putative allosteric sites in the acetylcholinesterase receptor. Journal of Molecular Graphics and Modelling, 2021: p. 107981.

127. Mandal, T., R.L. Marson, and R.G. Larson, Coarse-grained modeling of crystal growth and polymorphism of a model pharmaceutical molecule. Soft Matter, 2016. 12(39): p. 8246-8255.

128. Jha, P.K. and R.G. Larson, Assessing the efficiency of polymeric excipients by atomistic molecular dynamics simulations. Molecular pharmaceutics, 2014. 11(5): p. 1676-1686.

129. Rostamizadeh, E., et al., Green synthesis of Fe. sub. 2O. sub. 3 nanoparticles using fruit extract of Cornus mas L. and its growth-promoting roles in Barley. Journal of Nanostructure in Chemistry, 2020. 10(2): p. 125-131.

130. Han, S., Molecular dynamics simulation of sorbitan monooleate bilayers. Bulletin of the Korean Chemical Society, 2013. 34(3): p. 946-948.

131. Ritwiset, A., S. Krongsuk, and J.R. Johns, Molecular structure and dynamical properties of niosome bilayers with and without cholesterol incorporation: A molecular dynamics simulation study. Applied Surface Science, 2016. 380: p. 23-31.

132. Myung, Y., S. Yeom, and S. Han, A niosomal bilayer of sorbitan monostearate in complex with flavones: a molecular dynamics simulation study. Journal of liposome research, 2016. 26(4): p. 336-344.

133. Somjid, S., S. Krongsuk, and J.R. Johns, Cholesterol concentration effect on the bilayer properties and phase formation of niosome bilayers: a molecular dynamics simulation study. Journal of Molecular Liquids, 2018. 256: p. 591-598.

134. Barani, M., et al., In silico and in vitro study of magnetic niosomes for gene delivery: The effect of ergosterol and cholesterol. Materials Science and Engineering: C, 2019. 94: p. 234-246. 
135. Bhosale, R.R., et al., Current perspectives on novel drug carrier systems and therapies for management of pancreatic cancer: an updated inclusive review. Critical Reviews ${ }^{\mathrm{TM}}$ in Therapeutic Drug Carrier Systems, 2018. 35(3).

136. Su, C., et al., Absorption, distribution, metabolism and excretion of the biomaterials used in Nanocarrier drug delivery systems. Advanced drug delivery reviews, 2019. 143: p. 97-114.

137. Beck, T.C., et al., Descriptors of Cytochrome Inhibitors and Useful Machine Learning Based Methods for the Design of Safer Drugs. Pharmaceuticals, 2021. 14(5): p. 472.

138. Dong, J., et al., ADMETlab: a platform for systematic ADMET evaluation based on a comprehensively collected ADMET database. Journal of cheminformatics, 2018. 10(1): p. 1-11.

139. Xiong, G., et al., ADMETlab 2.0: an integrated online platform for accurate and comprehensive predictions of ADMET properties. Nucleic Acids Research, 2021.

140. Moss, D.M. and M. Siccardi, Optimizing nanomedicine pharmacokinetics using physiologically based pharmacokinetics modelling. British journal of pharmacology, 2014. 171(17): p. 3963-3979.

141. Farouk, F. and R. Shamma, Chemical structure modifications and nano-technology applications for improving ADME-Tox properties, a review. Archiv der Pharmazie, 2019. 352(2): p. 1800213.

142. Zolnik, B.S. and N. Sadrieh, Regulatory perspective on the importance of ADME assessment of nanoscale material containing drugs. Advanced drug delivery reviews, 2009. 61(6): p. 422-427.

143. Li, M., et al., Physiologically based pharmacokinetic (PBPK) modeling of pharmaceutical nanoparticles. The AAPS journal, 2017. 19(1): p. 26-42.

144. Badria, F.A., et al., Development of provesicular nanodelivery system of curcumin as a safe and effective antiviral agent: statistical optimization, in vitro characterization, and antiviral effectiveness. Molecules, 2020. 25(23): p. 5668.

145. Corbeil, C.R., C.I. Williams, and P. Labute, Variability in docking success rates due to dataset preparation. Journal of computer-aided molecular design, 2012. 26(6): p. 775-786.

146. Österberg, F., et al., Automated docking to multiple target structures: incorporation of protein mobility and structural water heterogeneity in AutoDock. Proteins: Structure, Function, and Bioinformatics, 2002. 46(1): p. 34-40.

147. Jones, G., P. Willett, and R.C. Glen, Molecular recognition of receptor sites using a genetic algorithm with a description of desolvation. Journal of molecular biology, 1995. 245(1): p. 43-53.

148. Zhao, H. and A. Caflisch, Discovery of ZAP70 inhibitors by high-throughput docking into a conformation of its kinase domain generated by molecular dynamics. Bioorganic \& medicinal chemistry letters, 2013. 23(20): p. 5721-5726.

149. Friesner, R.A., et al., Glide: a new approach for rapid, accurate docking and scoring. 1. Method and assessment of docking accuracy. Journal of medicinal chemistry, 2004. 47(7): p. 17391749.

150. Pagadala, N.S., K. Syed, and J. Tuszynski, Software for molecular docking: a review. Biophysical reviews, 2017. 9(2): p. 91-102.

151. Pinzi, L. and G. Rastelli, Molecular docking: shifting paradigms in drug discovery. International journal of molecular sciences, 2019. 20(18): p. 4331. 
152. Siepmann, J. and F. Siepmann, Modeling of diffusion controlled drug delivery. Journal of controlled release, 2012. 161(2): p. 351-362.

153. Abd-algaleel, S.A., et al., Evolution of the Computational Pharmaceutics Approaches in the Modeling and Prediction of Drug Payload in Lipid and Polymeric Nanocarriers. Pharmaceuticals, 2021. 14(7): p. 645.

154. Agarwal, S., et al., Formulation, characterization and evaluation of morusin loaded niosomes for potentiation of anticancer therapy. RSC advances, 2018. 8(57): p. 32621-32636.

155. Yinhua, D., et al., The synthesis, characterization, DNA/BSA/HSA interactions, molecular modeling, antibacterial properties, and in vitro cytotoxic activities of novel parent and niosome nanoencapsulated Ho (III) complexes. RSC Advances, 2020. 10(39): p. 22891-22908.

156. Pawar, S. and P. Vavia, Glucosamine anchored cancer targeted nano-vesicular drug delivery system of doxorubicin. Journal of drug targeting, 2016. 24(1): p. 68-79.

157. El-Halim, S.M.A., et al., Fabrication of anti-HSV-1 curcumin stabilized nanostructured proniosomal gel: molecular docking studies on thymidine kinase proteins. Scientia Pharmaceutica, 2020. 88(1): p. 9.

158. Moulahoum, H., et al., Potential effect of carnosine encapsulated niosomes in bovine serum albumin modifications. International journal of biological macromolecules, 2019. 137: p. 583-591.

159. Aboumanei, M.H. and A.F. Mahmoud, Design and development of a proniosomal transdermal drug delivery system of caffeine for management of migraine: In vitro characterization, 131I-radiolabeling and in vivo biodistribution studies. Process Biochemistry, 2020. 97: p. 201-212. 